
\title{
$\begin{array}{ll}\text { Research Square } & \begin{array}{l}\text { Preprints are preliminary reports that have not undergone peer review. } \\ \text { They should not be considered conclusive, used to inform clinical practice, } \\ \text { or referenced by the media as validated information. }\end{array}\end{array}$
}

\section{Different Gastrointestinal Microbiota Related to Bile- Acid Metabolism in Hypertensive Patients With or Without Nephropathy}

\section{XIN LI}

Department of General Medicine and Geriatrics, Yuhang Campus, the Second Zhejiang Hospital, School of Medicine, ZHejiang UNiversity

\section{WANG}

Department of Geriatrics, Renji Hospita, School of Medicine, Shanghai Jiaotong University

\section{SHAOJUN MA}

Department of Geriatrics, SHanghai 9th People's Hospital, School of Medicine, Shanghai Jiaotong University

\section{SHAOHUI LIN}

Department of Geriatrics, Shanghai 9th People's Hospital, School of Medicine, Shanghai Jiaotong University

\section{CHUNYAN WANG}

Shanghai Aikesuo Biomedical Technology L.L.C; Tomedex L.L.C https://orcid.org/0000-0003-24288494

HAIYA WANG ( $\square$ aksoinfo@126.com )

Shanghai Jiao Tong University https://orcid.org/0000-0003-2796-4902

\section{Research}

Keywords:

Posted Date: January 11th, 2021

DOI: https://doi.org/10.21203/rs.3.rs-142746/v1

License: (c) (i) This work is licensed under a Creative Commons Attribution 4.0 International License. Read Full License 


\section{Different Gastrointestinal Microbiota Related to Bile-Acid}

\section{Metabolism in Hypertensive Patients with or without Nephropathy}

\begin{tabular}{|c|c|c|c|c|}
\hline \# & Authors' Name & Authors' Ranking & Institutional Address & Email Address \\
\hline 1 & XIN LI & $\begin{array}{l}\text { Signed first for } \\
\text { joint first author }\end{array}$ & $\begin{array}{l}\text { Department of General } \\
\text { Medicine and Geriatrics, } \\
\text { Yuhang Campus, the } \\
\text { Second Zhejiang Hospital, } \\
\text { School of Medicine, Zhejiang } \\
\text { University, Yuhang District, } \\
\text { Nanwan St., Yingbin Rd.,No. } \\
\text { 369, Zhejiang Province } \\
\text { 311100, China.(1) } \\
\text { Before July 2020,when this } \\
\text { research started, } \\
\text { Department of Geriatrics, } \\
\text { Renji Hospital, School of } \\
\text { Medicine, Shanghai Jiao } \\
\text { Tong University, No.145, } \\
\text { Shandong Rd.Shanghai } \\
\text { 200001, China.(2) }\end{array}$ & 2508878651@qq.com \\
\hline 2 & LI WANG & $\begin{array}{l}\text { Signed second fo } \\
r \\
\text { joint first author }\end{array}$ & $\begin{array}{l}\text { Department of Geriatrics, } \\
\text { Renji Hospital, School of } \\
\text { Medicine, Shanghai Jiao } \\
\text { Tong University, No.145, } \\
\text { Shandong Rd.,Shanghai } \\
\text { 200001, China.(2) }\end{array}$ & ms wanlili@163.com \\
\hline 3 & SHAOJUN MA & $\begin{array}{l}\text { The second } \\
\text { author }\end{array}$ & $\begin{array}{l}\text { Department of Geriatrics, } \\
\text { Shanghai Ninth People's } \\
\text { Hospital, School of Medicine, } \\
\text { Shanghai Jiao Tong } \\
\text { University, No. } 639 \text { Zhizaoju } \\
\text { Rd., Shanghai } 200011, \\
\text { China.(3) }\end{array}$ & mashj@shsmu.edu.cn \\
\hline 4 & SHAOHUI LIN & The third author & $\begin{array}{l}\text { Department of Geriatrics, } \\
\text { Shanghai Ninth People's } \\
\text { Hospital, School of Medicine, } \\
\text { Shanghai Jiao Tong } \\
\text { University No. } 639 \text { Zhizaoju } \\
\text { Rd., Shanghai } 200011, \\
\text { China.(3) }\end{array}$ & shenhui1030@163.com \\
\hline \multirow[t]{2}{*}{5} & \multirow[t]{2}{*}{ CHUNYAN WANG } & \multirow[t]{2}{*}{$\begin{array}{l}\text { Signed second } \\
\text { co-corresponding } \\
\text { author }\end{array}$} & $\begin{array}{l}\text { Shanghai Aikesuo } \\
\text { Biomedical Technology } \\
\text { L.L.C, Shanghai, China.(4) }\end{array}$ & \multirow[t]{2}{*}{ chunyan02@yahoo.com } \\
\hline & & & $\begin{array}{l}6986 \text { Gregorich Dr. Unit E, } \\
\text { Tomedex L.L.C, San Jose, } \\
\text { California 95138, USA.(5) }\end{array}$ & \\
\hline \multirow[t]{2}{*}{6} & \multirow[t]{2}{*}{ HAIYA WANG } & \multirow[t]{2}{*}{$\begin{array}{l}\text { Signed first } \\
\text { co-corresponding } \\
\text { author }\end{array}$} & $\begin{array}{l}\text { Department of Geriatrics, } \\
\text { Shanghai Ninth People's } \\
\text { Hospital, School of Medicine, } \\
\text { Shanghai Jiao Tong } \\
\text { University. } \\
\text { No. } 639 \text { Zhizaoju } \\
\text { Rd.,Shanghai 200011, } \\
\text { China.(3) }\end{array}$ & \multirow[t]{2}{*}{ 18918179588@163.com } \\
\hline & & & $\begin{array}{l}\text { Department of Geriatrics, } \\
\text { Renji Hospital, School of } \\
\text { Medicine, Shanghai Jiao } \\
\text { Tong University, No.145, } \\
\text { Shandong Rd.Shanghai } \\
\text { 200001, China.(2) }\end{array}$ & \\
\hline
\end{tabular}




\section{Keywords}

Microbiota, Bile-Acids Metabolism, Hypertension, Nephropathy, Sequencing.

\section{Introduction}

Chronic kidney disease (CKD) is an important contributor to morbidity and mortality in the world. It has been recognized as a risk factor for cardiovascular disease and a risk multiplier in patients with hypertension and diabetes ${ }^{[1,2]}$. While impaired fasting plasma glucose, high blood pressure (HBP), high body-mass index, and a diet high in sodium were risk factors for CKD quantified in the Global Burden of Disease (GBD). This means early detection and treatment of diabetes, hypertension and CKD are readily available, inexpensive treatments to defer or prevent progression to the end-stage of kidney disease and cardiovascular events ${ }^{[3]}$. Despite major advances in the identification of key pathophysiological mechanisms and in treatment, hypertension remains one of the most important causes of acute and chronic cardiovascular disease ${ }^{[4,5]}$ It is believed that the etiology of hypertension depends on the complex interplay of both genetic and environmental factors ${ }^{[6-8]}[6-8]$. With the sequencing technology development, more and more researchers switched their attention from dietary components to gastrointestinal microbiota (GM) ${ }^{[9-11]}$.

The potential role of the GM in the altering health status of the hosts has drawn considerable attention. A number of microbial biomarkers specific to various diseases, such as colorectal cancer, liver cirrhosis, arthritis, type 2 diabetes, and atherosclerosis, have been discovered ${ }^{[12-15]}$. In addition, some studies found that changes in the structure of the intestinal flora are directly related to hypertension, and the richness and diversity of the intestinal flora in hypertensive patients have decreased significantly, specifically as Prevotella and Klebsiella 
significant increase, while the content of beneficial bacteria decreased ${ }^{[16]}$. Intestinal flora induced hypertension can also affect host gene expression and basic metabolic processes ${ }^{[17]}$ Some scientists believed that changes in intestinal microflora cause mutation of hepatic flavin monooxygenase-related genes and increase the genes expression ability as well as flavin monooxygenase synthesis, which indirectly leads to an increase in the incidence of hypertension by affecting the metabolism of trimethylamine oxide ${ }^{[18]}$. It is generally believed that the intestinal flora can also produce metabolites, such as Farnesoid X Receptor (FXR) signal antagonists, TGR5 signal agonists, $\beta$-taurocholic acid and other primary bile acids $[19,20]$, thereby promoting atherosclerosis and calcification of blood vessel walls by affecting cholesterol metabolism to indirectly affecting the occurrence and development of hypertension. In addition to multiple factors, such as genes, inflammation, and neuroendocrine system, changes in the intestinal microbiota attract our attention as a new target for diagnosis and treatment of hypertension.

The previous study found total bile acids (TBA) level of hypertensive patients is significantly higher than that of non-hypertensive patients, and the TBA level is related to the grade of hypertension, and has a certain correlation with the structural damage of the kidney and heart. TBA, a metabolite of cholesterol in the liver, provides a signal from the host to maintain the balance of the intestinal microecology through hepato-intestinal circulation ${ }^{[21,22]}$. Researchers are currently focusing on Bile Salt Hydrolase (BSH) which can enzymolyze the C-24-N-acyl bond of bile salt bound by glycine or taurine into free bile acid ${ }^{[22]}$. Many bacteria, such as Bacteroides, Clostridium, Lactobacillus, and Bifidobacteria, have BSH activity, which means the imbalance of intestinal flora may influence the metabolism of bile acids ${ }^{[23]}$. 
Considering TBA and GM are related to hypertension and kidney damage, and gut bacteria are involved in the metabolism of bile acid, we explored the relationship between GM and bile acid metabolism in patients with or without nephropathy.

\section{Results}

\section{- GM Diversity in Hypertension and Hypertension-related CKD (H-CKD)}

To determine whether changes in gut microbes are related to H-CKD, we studied the fecal microbiota in a well-characterized cohort that included 30 newly diagnosed hypertensive subjects without nephropathy and 11 patients with hypertensive nephropathy and 10 age, gender and BMI-matched normal controls. All selected patients provided stool samples under their approvals for $16 \mathrm{~S}$ rRNA gene sequencing and analysis. There are no significant differences in other characteristics, except for a family history of early-onset cardiovascular and cerebrovascular disease: Hypertension vs Normal $(p=0.00136) ; \mathrm{H}-\mathrm{CKD}$ vs Hypertension $(p=0.00106)$, by Kruskal-Wallis test. The detailed demographic, clinical and hypertensive features of the cohort are in Table1.

In this cohort study, rarefaction was performed that the total number of operational taxonomic units (OTUs) of these samples were estimated, the sequencing data were abundant enough that few new OTUs were found. Based on the genera profile, the Shannon index was calculated to estimate the within-sample ( $\alpha$ ) diversity. The rate of acquisition in the Normal group exceeded the one of new OTUs acquisition in Hypertensive groups, which indicates that the bacterial enrichment level of the Hypertensive groups is lower (Figure 1a). However, compared with the control group by the Kruskal-Wallis test, $\alpha$ diversity of the H-CKD and the Hypertension groups did not significantly decrease at the genus level (Figure 1b). In order to 
evaluate the overall diversity of microbial composition, we performed a principal coordinate analysis based on unweighted UniFrac distance and partial least square discriminant analysis (PLS-DA). The multivariate permutation test (MPT) showed that there were no significant differences in the composition of the intestinal taxonomy among the three groups (Figure 1c). However, PLS-DA showed that the difference and the distinction were significant among the groups when ignoring the random error (Figure 1d).

\section{- Bacteria Differential Abundance in Hypertension and H-CKD versus Controls}

To identify differential abundant taxa, we performed a linear discriminant analysis of effect (LEfSe) analysis on the fecal microbiota composition of the three groups. Bacteroidetes, Firmicutes and Proteobacteria were the most dominant phylum in all three groups (figure 2a). Meanwhile, Firmicutes/Bacteroidetes (F/B) in both $\mathrm{H}-\mathrm{CKD}$ and Hypertensive groups is significantly lower than it in Normal groups. No significant difference observed between Hypertension and H-CKD groups: H-CKD F/B=2.30; Hypertension $F / B=2.60$; Normal $F / B=0.90$. $H-C K D$ vs Normal $p=0.035$; Hypertension vs Normal, $p=0.035$; analyzed by Kruskal-Wallis test (Figure 2b). There were 19 bacterial taxa showing distinct relative abundances among the three groups; Linear Discriminant Analysis (LDA) score $>2.0, p<0.05$

(Figure. 2c; 2d). The contents of Coprococcus eutactus ( $p=0.006$, LDA score $=3.65$ ) and Ruminococcus torques $(\mathrm{p}=0.042$, LDA score $=3.63$ ) in the Hypertension with no nephropathy group were significantly increased, while the abundances of Veillonella parvula $(p=0.017$, LDA score $=3.28$ ) and Oxalobacter formigenes $(p=0.019$, LDA score $=3.73)$ were higher in the Hypertension with nephropathy group. Compared with the healthy controls, the abundances of Bacteroides ovatus $(p=0.047$, LDA score $=4.52)$, Clostridium ramsum $(p=0.015$, LDA 
score $=4.06)$, Prevotella copri $(p=0.018$, LDA score $=4.68)$ and Erysipelotrichia $(p=0.029$, LDA score $=4.01)$ in disease groups were significantly reduced.

\section{- Correlations between the Gut Microbiota and Bile Acid Metabolism}

In order to further study the correlation between clinical variables and disease-associated bacteria, we found that the mean levels of different types of bile acid were different in the $\mathrm{H}$ CKD, Hypertension and the Normal groups (Figure 3a). Although the level of total bile acid did not change significantly, the content of Chenodeoxycholic acid (CDCA) was significantly higher in the both H-CKD and Hypertension groups than in the Normal group. Meanwhile, the content of CDCA in Hypertension group was higher than that in the H-CKD group: Normal vs Hypertension $p=0.031$; Hpertension vs $\mathrm{H}-\mathrm{CKD} p=0.018$, by Mann-Whitney $U$ test (Figure $3 b$ ). The content of taurocholic acid of the H-CKD group was significantly higher than that of Hypertension group. However, there was no significance difference between Hypertension and Normal groups: Normal vs Hypertension $p>0.051$; Hypertension vs $\mathrm{H}-\mathrm{CKD} p=0.029$, by Mann-Whitney U test (Figure 3c).

In addition, we used Partial Spearman's rank-based correlation test to investigate whether the difference of bile acid profile is related to intestinal bacteria and found that deoxycholic acid was positive correlated with Anaerostipes $(R=0.46, P<0.01)$, Firmicutes $(R=0.37, P$ $<0.05)$ and Clostridium $(R=0.38, P<0.05)$; it was negatively correlated with Escherichia $(R$ $=-0.43, \mathrm{P}<0.01)$, Enterobacteriaceae $(\mathrm{R}=0.48, \mathrm{P}<0.05)$, and Proteobacteria $(\mathrm{R}=0.47, \mathrm{P}$ $<0.05)$. Glycodeoxycholic acid was negatively correlated with Escherichia $(R=-0.41, P<0.05)$ and was positively correlated with Oscillospira $(R=0.37, P<0.05)$. While Oscillospira was positively related to taurolithocholic acid $(R=0.38, P<0.05)$ and was negatively related to 
CDCA $(R=-0.37, P<0.05)$. The results showed that a negative correlation between Prevotella and taurochenodeoxycholic acid $(\mathrm{R}=-0.37, \mathrm{P}<0.01)$ and a positive correlation between Coprococcus and glycolithocholic acid $(R=0.32, P<0.05)$ (Figure 3d)

We inferred the metagenomes from the 16s rRNA gene data and analyzed the functional potential of the gut microbiome by PIRUST to investigate the functional changes of the microbial among the H-CKD, Hypertension, and Normal groups. Metabolism, genetic and environmental information processing are the main functions of the human gastrointestinal microbiota. However, no differences of these main functions were observed among H-CKD, Hypertension and Normal groups (Figure 4a). Through principal coordinate analysis, we found that the dominance functions of membrane transport, cell motility, signal transduction, cellular processes and signaling in H-CKD and Hypertension groups were stronger than those in the Normal group (Figure 4b). We also observed D-Glutamine ( $p=0.014$, Anova test) and D-glutamate metabolism, Glycosphingolipid biosynthesis - lacto and neolacto series ( $p=0.014$, Anova test) were significantly different between Hypertension and Normal groups.

\section{Discussion}

There is increasing evidence that changes in the intestinal microbiome are related to hypertension. In this research, we studied the structure of the fecal microbiome of hypertension with or without nephropathy by $16 \mathrm{~S}$ rRNA gene sequencing and analysis. The data showed that although there was no significant difference between healthy participants and hypertension with or without nephropathy, the microbial dysbiosis in the disease groups was characterized by changes in the relative abundance of the 19 bacterial genera. Then, we found that the CDCA level of hypertensive patients without nephropathy was higher than that 
of the Normal group and the Hypertension with nephropathy group. It may be related to the bile salt hydrolysis of Bacteroides and Clostridium.

All patients in the Hypertension and H-CKD groups were newly diagnosed hypertension or hypertension-related kidney disease. Although several studies ${ }^{[9,16,24]}$ discovered that the species richness and evenness of the hypertensive groups were low, the results of this study show that there is no statistical difference of the GM diversity in hypertensive patients with or without nephropathy groups and healthy controls. It may be related to the grade of hypertension ${ }^{[25]}$. Since only 51 subjects participated in our study, including 10 healthy controls, 30 hypertension patients, and 11 hypertensive nephropathy patients, we did not match them according to the grade of hypertension. We found that the F/B of the disease groups was significantly higher than that of the healthy control group, and Bacteroides is the dominant phylum of the healthy control group, consistent with previous animal studies ${ }^{[26]}$. This suggests that the composition of the intestinal microbiome is different in patients with simple hypertension or hypertensive nephropathy.

The most notable finding is that the characteristic flora of hypertension are Coprococcus eutactus and Ruminococcus torques, and the characteristic flora of hypertension-related nephropathy are Veillonella parvula (V. parvula) and Oxalobacter formigenes (O. formigenes), while the abundances of Bacteroides ovatus, Clostridium Ramsum, Prevotella copri (P.copri), and Erysipelothrix spp. of hypertension and H-CKD groups are lower than healthy controls. However, to figure out whether the characteristic flora of these three groups can accurately distinguish between hypertension and hypertensive nephropathy, it requires further research. 
The previous studies ${ }^{[27]}$ have proved that Coprococcus spp. has a high affinity for carbohydrates and can decompose carbohydrates to produce large amounts of butyric acid and acetic acid, also known as Short-Chain Fatty Acids (SCFAs). SCFAs are ligands for many G protein-coupled receptors (such as Gpr41, Gpr43, Gpr109a) and Olfactory receptor 78 (Olfr78), mainly found in the renal afferent arteriole and smooth muscle cells of the peripheral vascular system ${ }^{[28-30]}$. Renal afferent arterioles are the main place for storage and secretion of renin, which can increase blood pressure through the renin-angiotensinaldosterone pathway. The studies ${ }^{[31]}$ have shown that the combination of SCFA and Gpr41 can decrease blood pressure, while the combination of Olfr78 can increase the secretion of renin to raise blood pressure.

This physiological opposition may be related to the different ligand affinities of these two receptors. High concentrations of SCFAs may activate Olfr78 to increase blood pressure. Therefore, it is speculated that Coprococcus eutactus can produce more SCFAs from carbohydrates, exceeding the upper limitation to promote the development of hypertension. We also found that the abundance of $P$. copri is significantly lower in Hypertension and $\mathrm{H}$ CKD groups. It is affected by diet and lifestyle. The previous research ${ }^{[32]}$ suggested that $P$. copri in the intestine of people often taking in a large amount of high-fiber diet has a stronger ability to decompose carbohydrates, while $P$. copri in the intestine of people who have an omnivorous diet contains more leuB, a gene associated branched-chain amino acid synthesis related glucose tolerance and the risk of type-2 diabetes. However, MushtaqNosheenand et al. ${ }^{[25]}$ found that the abundance of $P$. copri in the hypertensive group was higher than that in the healthy controls. There is controversy regarding the beneficial or 
harmful effects of $P$. copri strain due to different diet patterns screened different $P$. copri strains, so the relationship between $P$. copri and hypertension still need further research. In addition, in the diabetic mouse model, it was found that $P$. copri was the predominant intestinal type, which means $P$. copri is related to diabetes ${ }^{[3]}$. Our results are different from the above studies, because we have ruled diabetes and other comorbidities out of the research subjects.

In the hypertensive nephropathy group, $O$. formigenes was the characteristic bacteria that is able to decompose oxalic acid to produce formic acid ${ }^{[34]}$. Oxalate is one of the uremic toxins in End-Stage Renal Disease (ESRD) patients. The increase of $O$. formigenes content is a compensatory process for the increase in oxalate ${ }^{[35]}$. In addition, our study also found $V$. parvula is the dominant bacteria in the patients with hypertensive nephropathy. $V$. parvula, a gram-positive bacteria with Lipopolysaccharide (LPS), is an opportunistic pathogen that usually parasitizes the human gastrointestinal tract and oral cavity. In the patients with hypertensive nephropathy, the excretion of various metabolites, such as secondary bile acid and trimethylamine oxide disorders, can destroy the intestinal mucosal barrier and cause LPS to enter the blood, thereby driving the immune response to release inflammatory factors and promote blood vessel walls oxidation, then leading to aggravating kidney damage ${ }^{[36]}$. However, the specificity of $V$. parvula is insufficient because it is also found in autoimmune hepatitis $^{[37]}$. The characteristic bacteria in hypertensive nephropathy we found might be different from those in other renal disease. A study on IgA nephropathy showed that the significantly increased genera in the IgAN group were Escherichia-Shigella, Hungatella and Eggerthella, all of which possess pathogenic potential[38,39]. Researchers identified 
Ruminococcus (Firmicutes phylum) that was associated negatively with renal function and positively with an indoxyl sulfate metabolite as well as 2 genera in the Lachnospiraceae family that were associated positively with renal function and negatively with phenylacetylglutamine metabolite ${ }^{[40]}$.Based on the correlation analysis of the influence of bile acid as an environmental factor on the intestinal flora, it was found that TCDCA was negatively correlated with Prevotella spp. Considering the hepatic and intestinal circulation mechanisms of bile acids, it is speculated that the increase in venous plasma TCDCA may inhibit the growth of Prevotella spp., therefore increasing blood pressure. However, there was no difference in TCDCA levels between the Hypertension group and the Healthy group. The content of CDCA in the Hypertension group was significantly higher than that in the healthy control. An animal experiment found that rats fed CDCA continuously had blood pressure increased from the 7th day and remained at a higher level after 14 days of continuous feeding $^{[41,42]}$. By correlation analysis, we found that CDCA levels are negatively correlated with Oscillatoria spp., a gram-positive anaerobic bacterium. Studies showed that the level of Oscillatoria spp. was related to vegetarian diet patterns ${ }^{[43]}$. Hence, we speculated that a vegetarian diet may be beneficial to blood pressure contro[ ${ }^{[44]}$. However, we didn't find the difference in Oscillatoria spp. among these three groups by LEfSe analysis.

Under the action of cholesterol 7- $\alpha$ dehydrogenase in the liver, cholesterol is decomposed to primary bile acids (CDCA and CA). Then Bile Acid-CoA Synthetase and Bile Acid-CoA (Amino Acid N-Acyltransferase) respectively combine with glycine and taurine to form GCDCA, GCA, TCA and TCDCA. They are then transported to the gallbladder for storage by a bile salt export pump. Under the action of bile salt hydrolase (BSH) in the intestine, the 
conjugated bile acids are decomposed into free bile acids. CA and CDCA are dehydroxylated to form secondary bile acids DCA and LCA respectively, which can re-enter the liver through the relevant transport proteins of hepatic intestinal circulation ${ }^{[45]}$. The previous research ${ }^{[46,47]}$ have found that Bacteroides spp. and Clostridia spp. have the effect of BSH to generate CA and CDCA. This is consistent with the increased levels of CDCA, Bacteroides spp. and Clostridia spp.in hypertensive participants in our study.

There was no statistical correlation found among Hypertension, H-CKD, and Normal groups in terms of DNA replication, repair, and certain amino acid metabolism. The PIRUST analysis, however, showed D-Glutamine and D-glutamate metabolism, Glycosphingolipid biosynthesislacto and neolacto series were significantly different $(p=0.014)$. Mels et al. ${ }^{[48]}$ found that the metabolism of D-Glutamine and D-glutamate is one of the metabolic pathways of hypertension. Oxidative inflammatory damage of the vascular endothelium is one of the pathogenesis of hypertension. Glutamate is an important substrate of glutathione which is an effective antioxidant in the human body. Therefore, it is speculated that the level of glutamate affects the level of glutathione that mediates the oxidative inflammation of the vessel wall and further participates in the occurrence of hypertension. Other researchers ${ }^{[49]}$ found that the synthesis of neutral glycosphingolipids in the brain of stress-induced hypertension rats was significantly inhibited, and the content of glycosphingolipids was significantly negatively correlated with the prognosis of acute stroke. This suggested Glycosphingolipid biosynthesislacto and neolacto series may be related to the compilations of hypertension. To find out the relationship between glutamate and glycosphingolipid metabolism pathways and hypertension, it needs further research with more samples. 
The main advantages of our research include collecting hypertensive nephropathy samples before renal protective interventions, using a cohort that includes any other diseases, discovering characteristic intestinal bacteria and preliminary discussion about the correlation between bile acid metabolism and GM in hypertension patients with or without nephropathy. Nevertheless, several limitations need to be noted. Firstly, all the samples were collected at the local hospital. The number of the samples in this cohort is not large enough, so our research is not universal but representative. Secondly, 16S rRNA gene sequencing has some disadvantages: 1 .The number of copies of each genome can vary; 2 . Although they tend to be specific taxa, there may be variation among strains; 3 . The relative abundance measurement is unreliable due to amplification bias; 4 .Genetic diversity tends to exaggerate estimates of diversity ${ }^{[50]}$. Thirdly, this study provides evidence of association rather than causation. Nonetheless, it provides new insights for preventing hypertension with or without nephropathy and also increases the possibility of using bacterial bio-markers to diagnose hypertensive nephropathy.

\section{Materials and Methods}

\section{- Study Design and Sample Collection}

All patient samples were newly diagnosed as primary hypertension or hypertension-related nephropathy in Renji Hospital, School of Medicine, Shanghai Jiaotong University, from September 2019 to December 2019. The diagnosis of hypertension was that systolic blood pressure (SBP) is $\geq 140 \mathrm{mmHg}$ and/or the diastolic blood pressure (DBP) is $\geq 90 \mathrm{mmHg}$ after repeated examination in hospital[51] Patients who meet the following two conditions can be diagnosed with hypertension-related nephropathy: (1) Essential hypertension; 
$30 \leq \mathrm{eGFR} \leq 60 \mathrm{ml} / \mathrm{min}$ and $/$ or urine albumin-creatinine ratio $(A C R) \geq 30 \mathrm{mg} / \mathrm{g}$. Finally, we collected a total of 51 individual stool samples for this research, including 10 healthy controls, 30 hypertensive patients with no nephropathy, and 11 patients with hypertensive nephropathy. Those healthy controls were selected from the volunteers to match the disease groups of patients with age, gender and body mass index (BMI). The exclusion criteria for the three groups were: (1) Patients with a history of diabetes or fasting blood glucose higher than $110 \mathrm{mg} / \mathrm{dL}(6.11 \mathrm{mmol} / \mathrm{L})$ or urinary albumin /creatinine $>2.5$; (2) Patients with primary or secondary increasing urinary protein or kidney damage such as rheumatic connective tissue disease, acute and chronic glomerulonephritis, multiple myeloma et al; (3) Patients with secondary hypertension such as protoaldehyde/adrenaline adenoma/renal artery stenosis/pituitary disease, etc.; (4) Cerebrovascular diseases occur within 2 months, such as cerebral hemorrhage, cerebral infarction, transient ischemic attack, subarachnoid hemorrhage, angina or myocardial infarction, PTCA, CABG, persistent atrial fibrillation and atrial flutter, combined with stenotic arteriosclerosis etc.; (5) Patients with a history of congenital and rheumatic heart disease, and cardiac insufficiency (NYHA cardiac function class III or higher); (6) Patients with a history of acute infection, acute bleeding or blood transfusion within 2 months, and taking any antibiotic and microbial preparation within 1 month; (7) Patients with severe liver and kidney dysfunction (eGFR less than 30), malignant tumors, inflammatory bowel disease, acute and chronic pancreatitis. This study was approved by the Ethics Committee of Renji Hospital, School of Medicine, Shanghai Jiaotong University, and all the subjects included in the study signed an informed consent. Stool samples from the individuals were all freshly collected in the hospital and frozen at $-80^{\circ} \mathrm{C}$ 
immediately after sampling. Meanwhile, we tested the fasting blood bile acids metabolism curve by high-performance liquid chromatography-mass spectrometry.

\section{- DNA Extraction and 16S rRNA Gene Sequencing}

We performed 16S rRNA gene sequencing. Briefly, after extracting bacterial genomic DNA by the E.Z.N.ATM Mag-Bind Soil DNA Kit(OMEGA, Switzerland), the 16S rRNA gene V3-V4 region was amplified by PCR and then sequenced by MiSeq platform (Illumina, San Diego, California, USA)

\section{- Bioinformatic Analysis of 16s rRNA Gene Sequencing}

The $16 \mathrm{~S}$ rRNA gene sequencing data were analyzed by Quantitative Insights into Microbial Ecology (QIIME) ${ }^{[52]}$. Then, we used vsearch plugin to cluster sequences into operational taxonomic units (OTUs) at $97 \%$ identity and the taxonomy was assigned against the Greengenes database (V.13.8). After filtering, each sample gets an average of 72473 reads of alpha value, and uses q2 diversity to perform $\beta$ diversity analysis at 2500 rare sampling depths. The metagenomes of gut microbiome were imputed from 16S rRNA gene sequences by PICRUSt (Phylogenetic Investigation of Communities by Reconstruction of Unobserved States) $)^{[53]}$.

\section{- Statistical Analysis}

We applied LEfSe analysis to determine the abundance of taxa or pathway differences between cases and controls ${ }^{[54]}$. This method firstly uses the non-parametric factorial KruskalWallis sum-rank test to detect features with significant differential abundance and then uses linear discriminant analysis (LDA) to calculate the effect size of each feature. 
The relationship between the microbiota and bile acid profile was analyzed by canonical correspondence analysis/redundancy analysis (CCA/RDA) $)^{[55]}$. The R pheatmap package was used to analyze whether the microbiome was significantly correlated with bile acid, and to calculate the Spearman coefficient ${ }^{[56]}$. The function of the microbiome was analyzed by the Kyoto Encyclopedia of Genes and Genomes (KEEG ) [57], the predictive function was analyzed by ANOVA and Dunnett's test to see if there were significant differences among the groups.

Statistical analyses were performed with $R(V$ 3.51). We used multivariate stepwise logistic regression analysis and the caret package to identify the genera that best distinguished hypertensive patients with or without nephropathy from controls. Other statistical analysis tools included Fisher's exact test, Kruskal-Wallis test and partial Spearman's rank correlation (PResiduals package).

\section{Conclusion}

The overall composition of the intestinal microbes has no significant difference in diversity, compared with hypertension and healthy controls. F/B increases significantly in hypertensive patients.

The intestinal characteristic flora of hypertension with no nephropathy is Coprococcus eutactus and Ruminococcus torques; this flora of hypertension with nephropathy is Veillonella parvula and Oxalobacter formigenes; and it of the healthy population is Bacteroides ovatus, Clostridium ramsum, Prevotella copri and Erysipelothrix spp.

The characteristics of the intestinal flora may be used as a diagnostic biomarker for hypertension-related nephropathy. The use of probiotics may help prevent nephropathy and 
cardiovascular disease.

The CDCA level of hypertensive patients without nephropathy is higher than that of healthy controls and hypertensive nephropathy patients. It may be related to the bile-salt hydrolysis of Bacteroides and Clostridium.

\section{Declarations}

- Ethics approval and consent to participate

This study was approved by the Ethics Committee of Renji Hospital, School of Medicine, Shanghai Jiaotong University, and all the subjects signed the consent form to participate in the study.

Following are the pictures of "Shanghai Jiaotong University School of Medicine, Renji Hospital Ethics Committee Approval Letter". The "Approval Document No." is KY2020017.
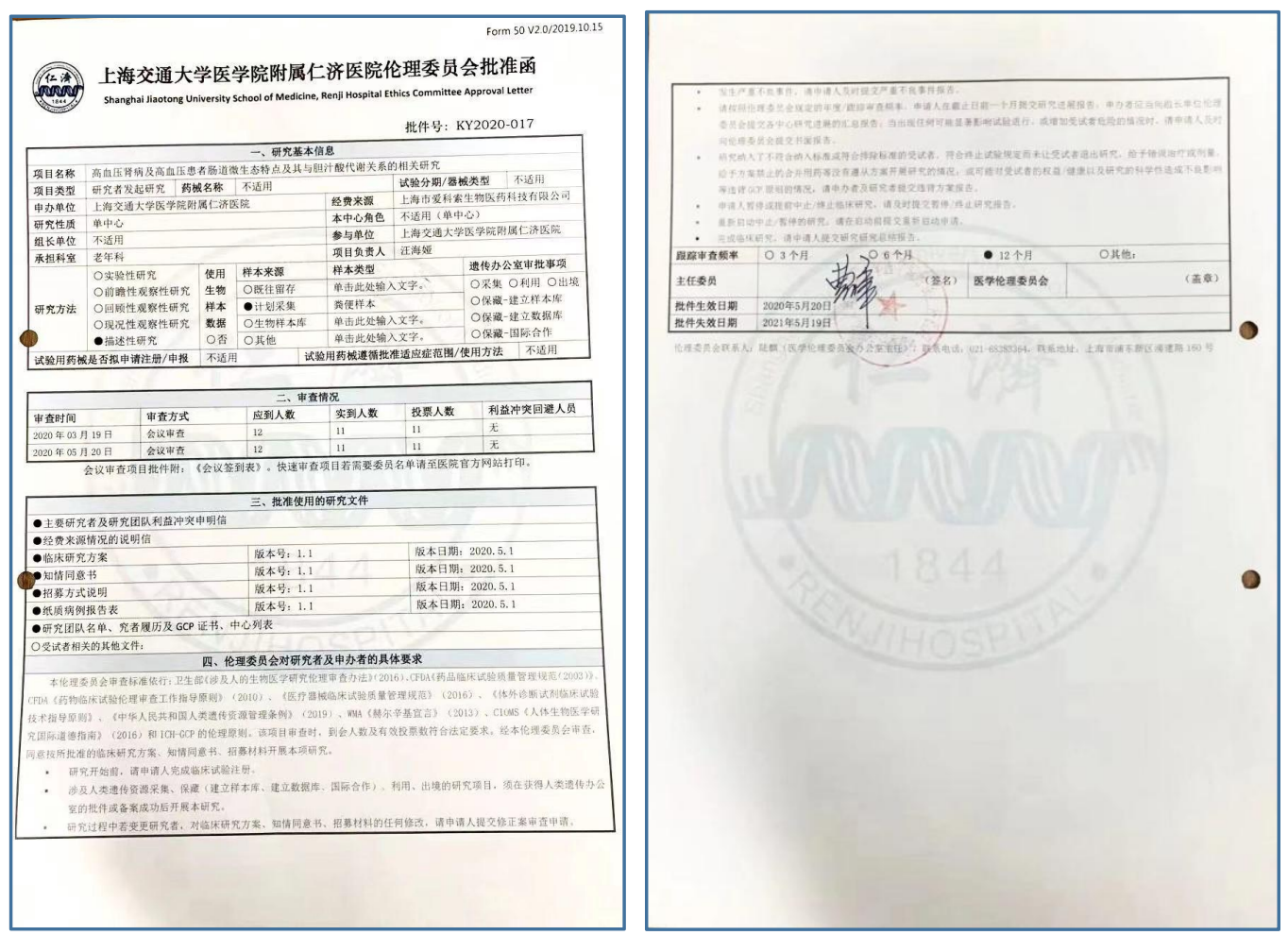


\section{- Consent for publication}

There manuscript contains no individual person's data in any form.

- Availability of data and materials statement

The data that support the findings of this study are available from the first author and the corresponding author upon reasonable request.

\section{- Competing interests}

The authors declare that they have no competing interests.

\section{- Funding}

The funding was donated by Shanghai Aikesuo Biomedical Technology L.L.C.

- Acknowledgements

None

\section{- Authors' contributions}

\begin{tabular}{|c|l|l|l|}
\hline$\#$ & Authors' Name & \multicolumn{1}{|c|}{ Author Ranking } & \multicolumn{1}{|c|}{ Authors' contributions } \\
\hline 1 & Xin Li & $\begin{array}{l}\text { Signed first for joint } \\
\text { first author. }\end{array}$ & $\begin{array}{l}\text { Brewing and designing experiments; Research } \\
\text { implementation; Dat collection; Data } \\
\text { analysis/interpretation; Statistical analysis; Article } \\
\text { drafting. }\end{array}$ \\
\hline 2 & Li Wang & $\begin{array}{l}\text { Signed second for joint } \\
\text { first author. }\end{array}$ & $\begin{array}{l}\text { Brewing and designing experiments; Research } \\
\text { implementation; Data collection; Experiment; } \\
\text { Statistical analysis; Article draft revision. }\end{array}$ \\
\hline 3 & Shaojun Ma & The second author. & $\begin{array}{l}\text { Data collection; Samples collection and } \\
\text { management. }\end{array}$ \\
\hline 4 & Shaohui Lin & The third author. & Sample management; Supporting contribution. \\
\hline 5 & Chunyan Wang & $\begin{array}{l}\text { Signed second co- } \\
\text { corresponding author }\end{array}$ & $\begin{array}{l}\text { Brewing and designing experiments; Research } \\
\text { implementation; Genome sequencing and } \\
\text { analysis/interpretation; Research funding; } \\
\text { Critically review the intellectual content of the } \\
\text { article. }\end{array}$ \\
\hline 6 & Haiya Wang & $\begin{array}{l}\text { Signed first co- } \\
\text { corresponding author }\end{array}$ & $\begin{array}{l}\text { Brewing and designing experiments; } \\
\text { Implementation research; Critically review the } \\
\text { intellectual content of the article; Research } \\
\text { funding; Administrative, technical or material } \\
\text { support. }\end{array}$ \\
\hline
\end{tabular}


- Authors' information

\begin{tabular}{|c|c|c|c|c|}
\hline \# & Authors' Name & Authors' Titles & Institutional Address & Email Address \\
\hline \multirow[t]{2}{*}{1} & \multirow[t]{2}{*}{ Xin Li } & $\begin{array}{l}\text { Resident } \\
\text { Physician }\end{array}$ & $\begin{array}{l}\text { Department of General Medicine } \\
\text { and Geriatrics, Yuhang } \\
\text { Campus, the Second Zhejiang } \\
\text { Hospital, School of Medicine, } \\
\text { Zhejiang University, Yuhang } \\
\text { District, Nanwan St., Yingbin } \\
\text { Rd.,No. 369, Zhejiang Province } \\
\text { 311100, China. }\end{array}$ & \multirow[t]{2}{*}{ 2508878651@qq.com } \\
\hline & & $\begin{array}{l}\text { Graduate } \\
\text { Student }\end{array}$ & $\begin{array}{l}\text { Before July 2020, when this } \\
\text { research started, Department of } \\
\text { Geriatrics, Renji Hospital, } \\
\text { School of Medicine, Shanghai } \\
\text { Jiao Tong University, Shanghai, } \\
\text { China. }\end{array}$ & \\
\hline 2 & Li Wang & $\begin{array}{l}\text { Attending } \\
\text { Physician }\end{array}$ & $\begin{array}{l}\text { Department of Geriatrics, Renji } \\
\text { Hospital, School of Medicine, } \\
\text { Shanghai Jiao Tong University, } \\
\text { No.145, Shandong Rd.Shanghai } \\
200001 \text {, China. }\end{array}$ & ms wanlili@163.com \\
\hline 3 & Shaojun Ma & $\begin{array}{l}\text { Physician } \\
\text { Deputy Chief }\end{array}$ & $\begin{array}{l}\text { Department of Geriatrics, } \\
\text { Shanghai Ninth People's } \\
\text { Hospital, School of Medicine, } \\
\text { Shanghai Jiao Tong University, } \\
\text { No. } 639 \text { Zhizaoju Rd, Shanghai } \\
\text { 200011, China. }\end{array}$ & mashj@shsmu.edu.cn \\
\hline 4 & Shaohui Lin & $\begin{array}{l}\text { Resident } \\
\text { Physician }\end{array}$ & $\begin{array}{l}\text { Department of Geriatrics, } \\
\text { Shanghai Ninth People's } \\
\text { Hospital, School of Medicine, } \\
\text { Shanghai Jiao Tong University } \\
\text { No. } 639 \text { Zhizaoju Rd, Shanghai } \\
\text { 200011, China. }\end{array}$ & Shenhui1030@163.com \\
\hline \multirow[t]{2}{*}{5} & \multirow[t]{2}{*}{ Chunyan Wang } & $\begin{array}{l}\text { Chief } \\
\text { Technology } \\
\text { Officer }\end{array}$ & $\begin{array}{l}\text { Shanghai Aikesuo Biomedical } \\
\text { Technology L.L.C, Shanghai, } \\
\text { China. }\end{array}$ & \multirow[t]{2}{*}{$\begin{array}{l}\text { Chunyan02@yahoo.com } \\
\text { Cell:314-4405423 }\end{array}$} \\
\hline & & President & $\begin{array}{l}6986 \text { Gregorich Dr. Unit E, } \\
\text { Tomedex L.L.C, San Jose, } \\
\text { California 95138, USA. }\end{array}$ & \\
\hline \multirow[t]{2}{*}{6} & \multirow[t]{2}{*}{ Haiya Wang } & $\begin{array}{l}\text { Director } \\
\text { Chief Physician }\end{array}$ & $\begin{array}{l}\text { Department of Geriatrics, } \\
\text { Shanghai Ninth People's } \\
\text { Hospital, School of Medicine, } \\
\text { Shanghai Jiao Tong University. } \\
\text { No. } 639 \text { Zhizaoju Rd,Shanghai } \\
\text { 200011, China. }\end{array}$ & \multirow[t]{2}{*}{ 18918179588@163.com } \\
\hline & & Chief Physician & $\begin{array}{l}\text { Department of Geriatrics, Renji } \\
\text { Hospital, School of Medicine, } \\
\text { Shanghai Jiao Tong University, } \\
\text { No.145, Shandong Rd.Shanghai } \\
200001 \text {, China. }\end{array}$ & \\
\hline
\end{tabular}




\section{References}

[1] Global, regional, and national burden of chronic kidney disease, 1990-2017: a systematic analysis for the Global Burden of Disease Study 2017[J]. Lancet (London, England), 2020, 395(10225): 709-733.

[2] Gansevoort R T, Correa-Rotter R, Hemmelgarn B R, et al. Chronic kidney disease and cardiovascular risk: epidemiology, mechanisms, and prevention[J]. The Lancet, 2013, 382(9889): 339-352.

[3] Webster A C, Nagler E V, Morton R L, et al. Chronic Kidney Disease[J]. The Lancet, 2017, 389(10075): 1238-1252.

[4] Writing Group M, Mozaffarian D, Benjamin E J, et al. Heart Disease and Stroke Statistics2016 Update: A Report From the American Heart Association[J]. Circulation, 2016, 133(4): e38-360.

[5] Hamrahian S M, Falkner B. Hypertension in Chronic Kidney Disease[J]. Adv Exp Med Biol, 2017, 956: 307-325.

[6] Arnett D K, Claas S A. Omics of Blood Pressure and Hypertension[J]. Circ Res, 2018, 122(10): 1409-1419.

[7] Hoffmann T J, Ehret G B, Nandakumar P, et al. Genome-wide association analyses using electronic health records identify new loci influencing blood pressure variation[J]. Nat Genet, 2017, 49(1): 54-64.

[8] Ormesher L, Myers J E, Chmiel C, et al. Effects of dietary nitrate supplementation, from beetroot juice, on blood pressure in hypertensive pregnant women: A randomised, doubleblind, placebo-controlled feasibility trial[J]. Nitric Oxide, 2018, 80: 37-44. 
[9] Marques F Z, Mackay C R, Kaye D M. Beyond gut feelings: how the gut microbiota regulates blood pressure[J]. Nature reviews. Cardiology, 2018, 15(1): 20-32.

[10] Yang F, Sun L, Zhu X, et al. Correction: Identification of new genetic variants of HLADQB1 associated with human longevity and lipid homeostasis-a cross-sectional study in a Chinese population[J]. Aging, 2018, 10(3): 515-515.

[11] Sun W, Guo Y, Zhang S, et al. Fecal Microbiota Transplantation Can Alleviate Gastrointestinal Transit in Rats with High-Fat Diet-Induced Obesity via Regulation of Serotonin Biosynthesis[J]. BioMed Research International, 2018, 2018: 1-9.

[12] Ricciuto A, Sherman P M, Laxer R M. Gut microbiota in chronic inflammatory disorders: A focus on pediatric inflammatory bowel diseases and juvenile idiopathic arthritis[J]. Clin Immunol, 2020, 215: 108415.

[13] Cueva C, Silva M, Pinillos I, et al. Interplay between Dietary Polyphenols and Oral and Gut Microbiota in the Development of Colorectal Cancer[J]. Nutrients, 2020, 12(3).

[14] Acharya C, Sahingur S E, Bajaj J S. Microbiota, cirrhosis, and the emerging oral-gut-liver axis[J]. JCI Insight, 2017, 2(19).

[15] Salgaco M K, Oliveira L G S, Costa G N, et al. Relationship between gut microbiota, probiotics, and type 2 diabetes mellitus[J]. Appl Microbiol Biotechnol, 2019, 103(23-24): $9229-9238$.

[16] Li J, Zhao F, Wang Y, et al. Gut microbiota dysbiosis contributes to the development of hypertension[J]. Microbiome, 2017, 5(1): 14. 
[17] Robles-Vera I, Toral M, De La Visitacion N, et al. The Probiotic Lactobacillus fermentum Prevents Dysbiosis and Vascular Oxidative Stress in Rats with Hypertension Induced by Chronic Nitric Oxide Blockade[J]. Mol Nutr Food Res, 2018, 62(19): e1800298.

[18] Wang X, Yang S, Li S, et al. Aberrant gut microbiota alters host metabolome and impacts renal failure in humans and rodents[J]. Gut, 2020.

[19] Pols T W, Nomura M, Harach T, et al. TGR5 activation inhibits atherosclerosis by reducing macrophage inflammation and lipid loading[J]. Cell Metab, 2011, 14(6): 747-57.

[20] Wahlstrom A, Kovatcheva-Datchary P, Stahlman M, et al. Crosstalk between Bile Acids and Gut Microbiota and Its Impact on Farnesoid X Receptor Signalling[J]. Dig Dis, 2017, 35(3): 246-250.

[21] Chiang J Y. Bile acid metabolism and signaling[J]. Compr Physiol, 2013, 3(3): 1191-212.

[22] Wahlstrom A, Sayin S I, Marschall H U, et al. Intestinal Crosstalk between Bile Acids and Microbiota and Its Impact on Host Metabolism[J]. Cell Metab, 2016, 24(1): 41-50.

[23] Kang J D, Myers C J, Harris S C, et al. Bile Acid 7alpha-Dehydroxylating Gut Bacteria Secrete Antibiotics that Inhibit Clostridium difficile: Role of Secondary Bile Acids[J]. Cell Chem Biol, 2019, 26(1): 27-34 e4.

[24] Sun S, Lulla A, Sioda M, et al. Gut Microbiota Composition and Blood Pressure[J]. Hypertension, 2019, 73(5): 998-1006.

[25] Mushtaq N, Hussain S, Zhang S, et al. Molecular characterization of alterations in the intestinal microbiota of patients with grade 3 hypertension[J]. International journal of molecular medicine, 2019, 44(2): 513-522. 
[26] Santisteban M M, Qi Y, Zubcevic J, et al. Hypertension-Linked Pathophysiological Alterations in the Gut[J]. Circulation Research, 2017, 120(2): 312-323.

[27] Healey G, Murphy R, Butts C, et al. Habitual dietary fibre intake influences gut microbiota response to an inulin-type fructan prebiotic: a randomised, double-blind, placebocontrolled, cross-over, human intervention study[J]. British Journal of Nutrition, 2018, 119(2): 176-189.

[28] Felizardo R J F, Watanabe I K M, Dardi P, et al. The interplay among gut microbiota, hypertension and kidney diseases: The role of short-chain fatty acids[J]. Pharmacol Res, 2019, 141: 366-377.

[29] Pluznick J L. Gut microbiota in renal physiology: focus on short-chain fatty acids and their receptors[J]. Kidney Int, 2016, 90(6): 1191-1198.

[30] Pluznick J L. Microbial Short-Chain Fatty Acids and Blood Pressure Regulation[J]. Current hypertension reports, 2017, 19(4): 25.

[31] Natarajan N, Hori D, Flavahan S, et al. Microbial short chain fatty acid metabolites lower blood pressure via endothelial G protein-coupled receptor 41[J]. Physiological genomics, 2016, 48(11): 826-834.

[32] De Filippis F, Pasolli E, Tett A, et al. Distinct Genetic and Functional Traits of Human Intestinal Prevotella copri Strains Are Associated with Different Habitual Diets[J]. Cell host \& microbe, 2019, 25(3).

[33] Gu Y, Wang X, Li J, et al. Analyses of gut microbiota and plasma bile acids enable stratification of patients for antidiabetic treatment[J]. Nature communications, 2017, 8(1): 1785. 
[34] Jairath A, Parekh N, Otano N, et al. Oxalobacter formigenes: Opening the door to probiotic therapy for the treatment of hyperoxaluria[J]. Scand J Urol, 2015, 49(4): 334-7.

[35] Hoppe B, Pellikka P A, Dehmel B, et al. Effects of Oxalobacter formigenes in subjects with primary hyperoxaluria Type 1 and end-stage renal disease: a Phase II study[J]. Nephrol Dial Transplant, 2020.

[36] Chen $Y Y$, Chen D Q, Chen L, et al. Microbiome-metabolome reveals the contribution of gut-kidney axis on kidney disease[J]. J Transl Med, 2019, 17(1): 5.

[37] Wei Y, Li Y, Yan L, et al. Alterations of gut microbiome in autoimmune hepatitis[J]. Gut, 2020, 69(3): 569-577.

[38] De Angelis M, Montemurno E, Piccolo M, et al. Microbiota and metabolome associated with immunoglobulin A nephropathy (IgAN)[J]. PLoS One, 2014, 9(6): e99006.

[39] Hu X, Du J, Xie Y, et al. Fecal microbiota characteristics of Chinese patients with primary IgA nephropathy: a cross-sectional study[J]. BMC Nephrol, 2020, 21(1): 97.

[40] Chung S, Barnes J L, Astroth K S. Gastrointestinal Microbiota in Patients with Chronic Kidney Disease: A Systematic Review[J]. Adv Nutr, 2019, 10(5): 888-901.

[41] Morris D J, Latif S A, Brem A S. An alternative explanation of hypertension associated with 17a-hydroxylase deficiency syndrome[J]. Steroids, 2014, 79: 44-48.

[42] Morris D J, Souness G W. Endogenous 11 beta-hydroxysteroid dehydrogenase inhibitors and their role in glucocorticoid $\mathrm{Na}+$ retention and hypertension[J]. Endocr Res, 2012, 22(4): 793-801. 
[43] Mackie R I, Aminov R I, Hu W, et al. Ecology of uncultivated Oscillospira species in the rumen of cattle, sheep, and reindeer as assessed by microscopy and molecular approaches[J]. Appl Environ Microbiol, 2003, 69(11): 6808-15.

[44] Rizza W, Veronese N, Fontana L. What are the roles of calorie restriction and diet quality in promoting healthy longevity?[J]. Ageing Res Rev, 2014, 13: 38-45.

[45] He Y, Wu W, Zheng $\mathrm{H} \mathrm{M}$, et al. Regional variation limits applications of healthy gut microbiome reference ranges and disease models[J]. Nat Med, 2018, 24(10): 1532-1535.

[46] Song Z, Cai Y, Lao X, et al. Taxonomic profiling and populational patterns of bacterial bile salt hydrolase (BSH) genes based on worldwide human gut microbiome[J]. Microbiome, 2019, 7(1): 9.

[47] Jia W, Xie G, Jia W. Bile acid-microbiota crosstalk in gastrointestinal inflammation and carcinogenesis[J]. Nat Rev Gastroenterol Hepatol, 2018, 15(2): 111-128.

[48] Mels C M, Delles C, Louw R, et al. Central systolic pressure and a nonessential amino acid metabolomics profile: the African Prospective study on the Early Detection and Identification of Cardiovascular disease and Hypertension[J]. J Hypertens, 2019, 37(6): 11571166.

[49] Ortiz A, Abiose A, Bichet D G, et al. Time to treatment benefit for adult patients with Fabry disease receiving agalsidase beta: data from the Fabry Registry[J]. J Med Genet, 2016, 53(7): 495-502.

[50] Phd W W. Unculturable bacteriaĐthe uncharacterized organismsthat cause oral infections[J]. Journal of translational medicine, 2002, 95: 8-13. 
[51] Unger T, Borghi C, Charchar F, et al. 2020 International Society of Hypertension Global Hypertension Practice Guidelines[J]. Hypertension, 2020, 75(6): 1334-1357.

[52] Navas-Molina J A, Peralta-Sanchez J M, Gonzalez A, et al. Advancing our understanding of the human microbiome using QIIME[J]. Methods Enzymol, 2013, 531: 371444.

[53] Langille M G, Zaneveld J, Caporaso J G, et al. Predictive functional profiling of microbial communities using 16S rRNA marker gene sequences[J]. Nat Biotechnol, 2013, 31(9): 81421.

[54] Nicola Segata J I, Levi Waldron, Dirk Gevers, Larisa Miropolsky, Wendy S Garrett and Curtis Huttenhower. Metagenomic biomarker discovery and explanation[J]. Genome Biology, 2011.

[55] Buttigieg P L, Ramette A. A guide to statistical analysis in microbial ecology: a community-focused, living review of multivariate data analyses[J]. FEMS Microbiol Ecol, 2014, 90(3): 543-50.

[56] Paliy O, Shankar V. Application of multivariate statistical techniques in microbial ecology[J]. Mol Ecol, 2016, 25(5): 1032-57.

[57] Comeau A M, Douglas G M, Langille M G. Microbiome Helper: a Custom and Streamlined Workflow for Microbiome Research[J]. mSystems, 2017, 2(1). 


\section{Figures and Tables}

- Figure 1

Figure 1a

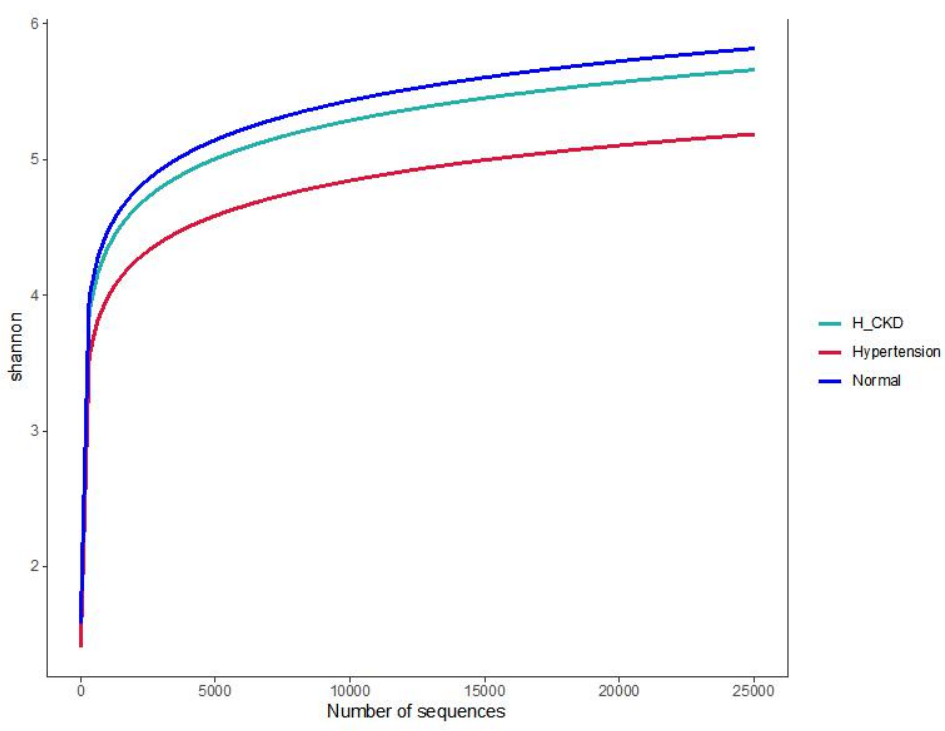

Figure $1 \mathrm{~b}$

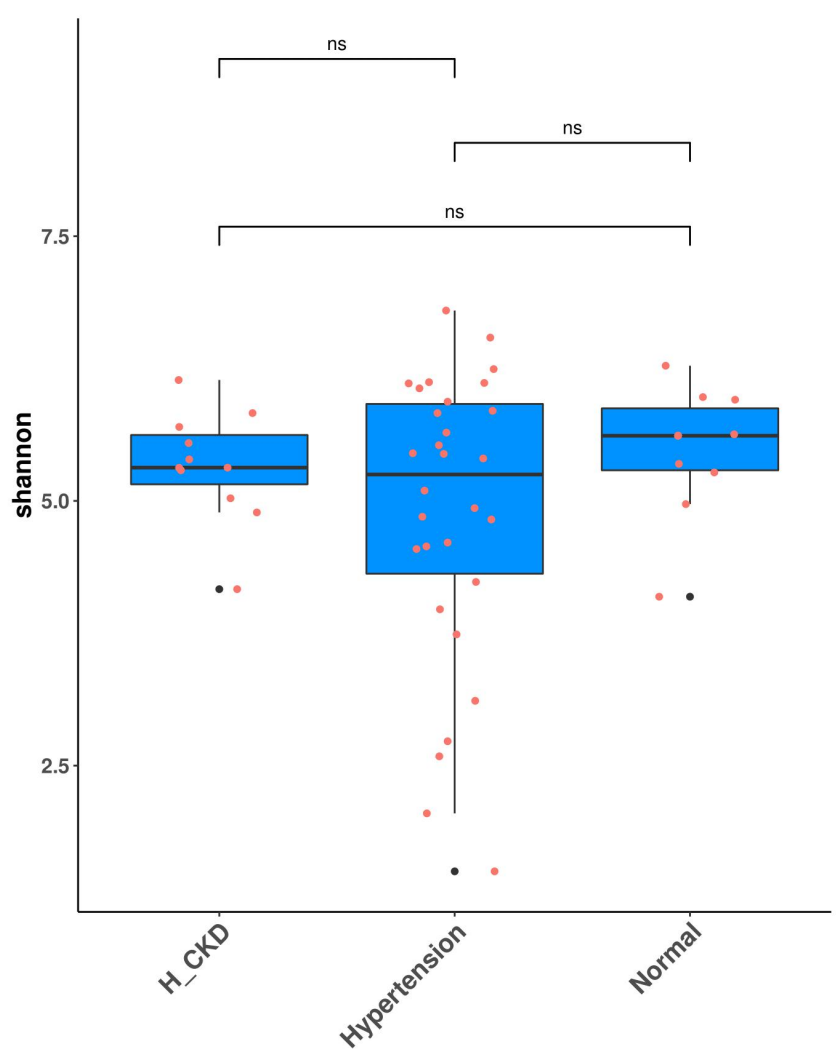


Figure 1c

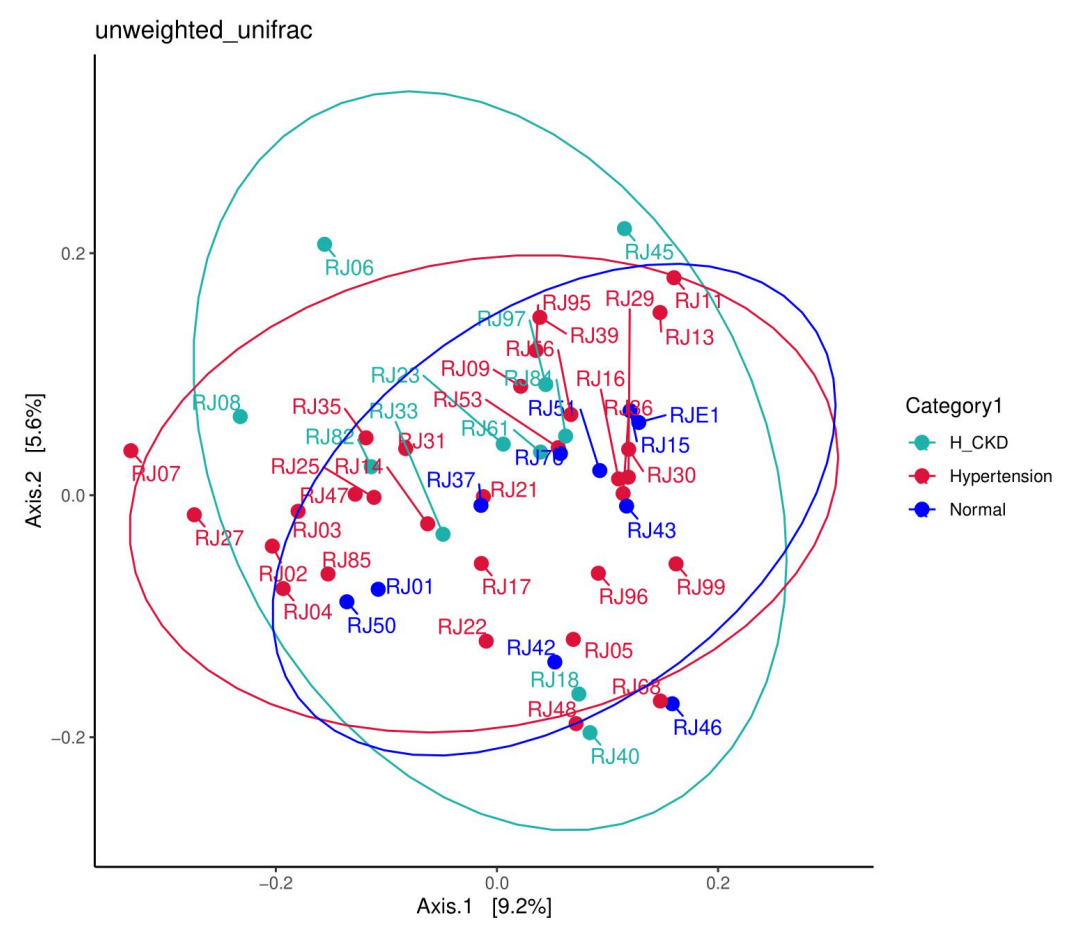

Figure 1d

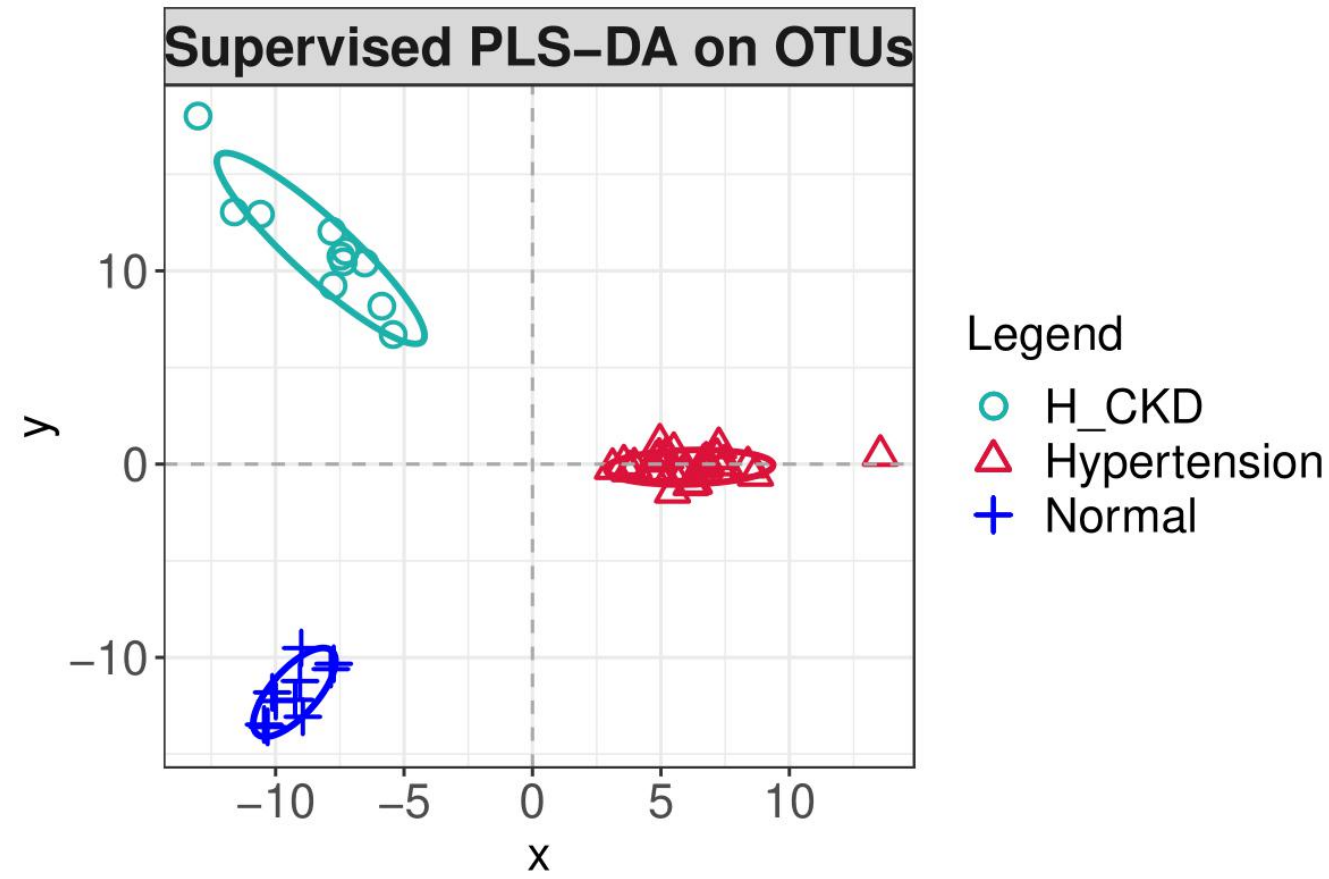


Figure 1: Comparisons of Alpha-diversity and Beta-diversity among the Groups of H-CKD, Hypertension and Normal

(a) Rarefaction curves for the mean of Shannon index in the three groups. The curve in each group is near smooth when the sequencing data is abundant enough with few new OTUs undetected; (b) Comparison of diversity in the three groups accessed by Shannon index. Compared with the control group tested by Kruskal-Wallis, the a diversity of H-CKD group and hypertensive groups did not significantly decrease at the genus level; (c) Based on the unweighted UniFrac matrix, PCoA showed that the overall fecal microbiota composition of the three groups was similar; (d) PL

(b) S-DA shows the significant distinction among the three groups.

OTU, operational taxonomic units; PCoA, principal coordinate analysis; PLS-DA, Partial Least Squares Discrimination Analysis.

\section{- $\quad$ Figure 2}

Figure 2a

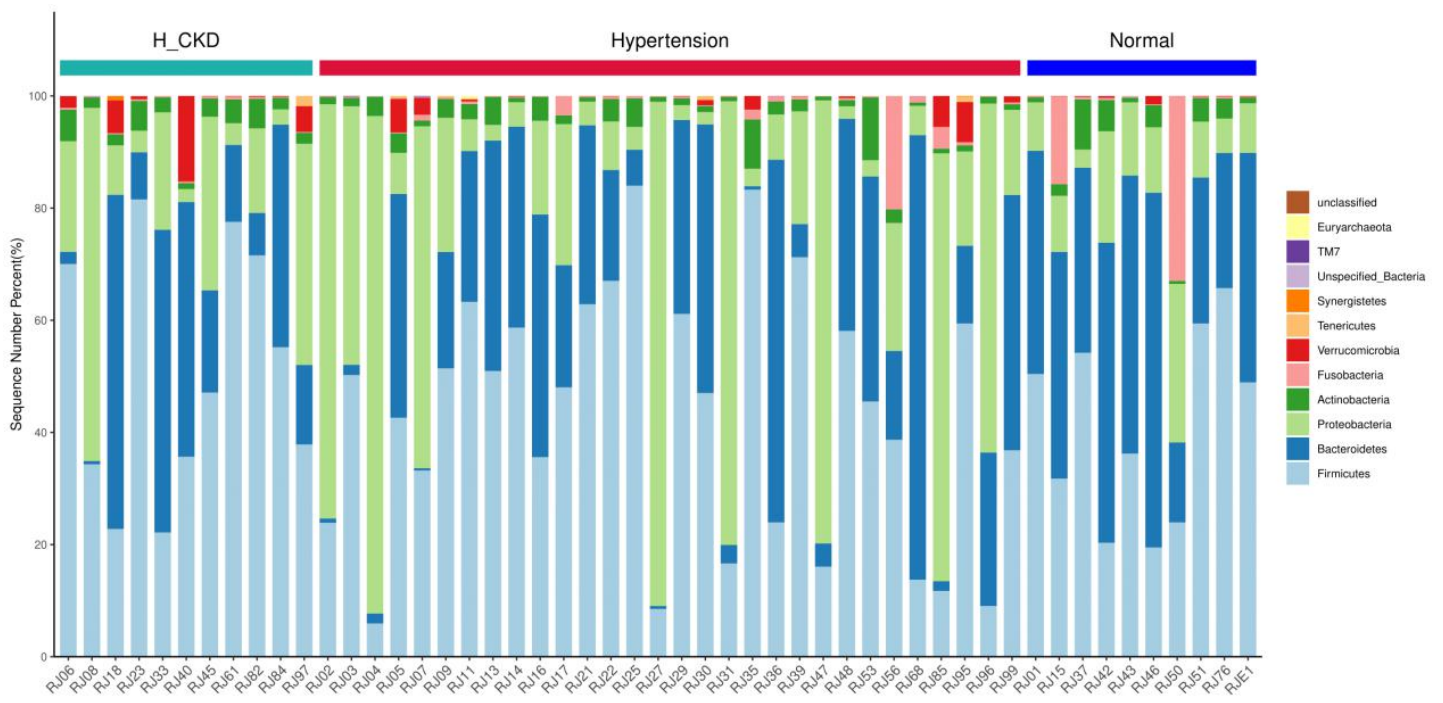


Figure $2 b$

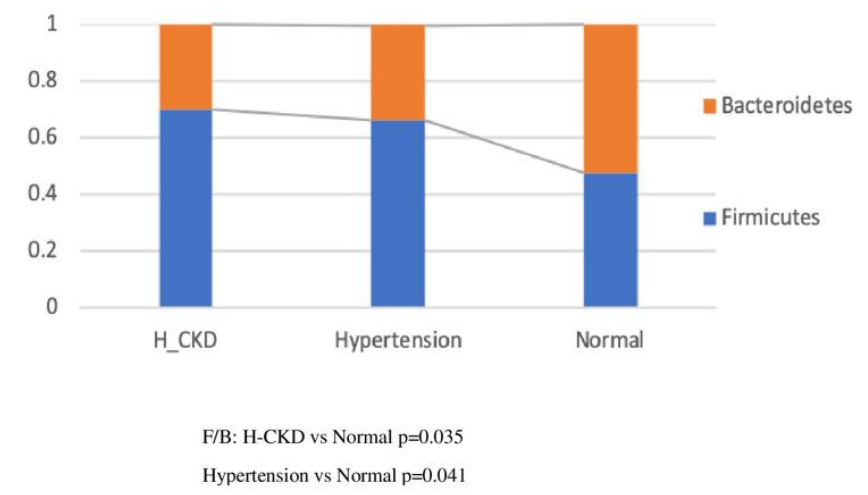

Figure 2c

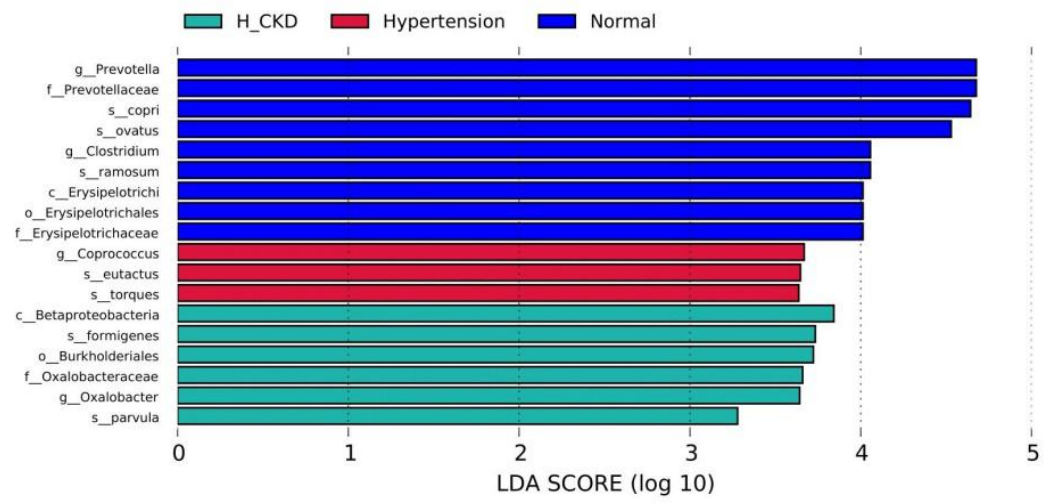

Figure 2d

Cladogram
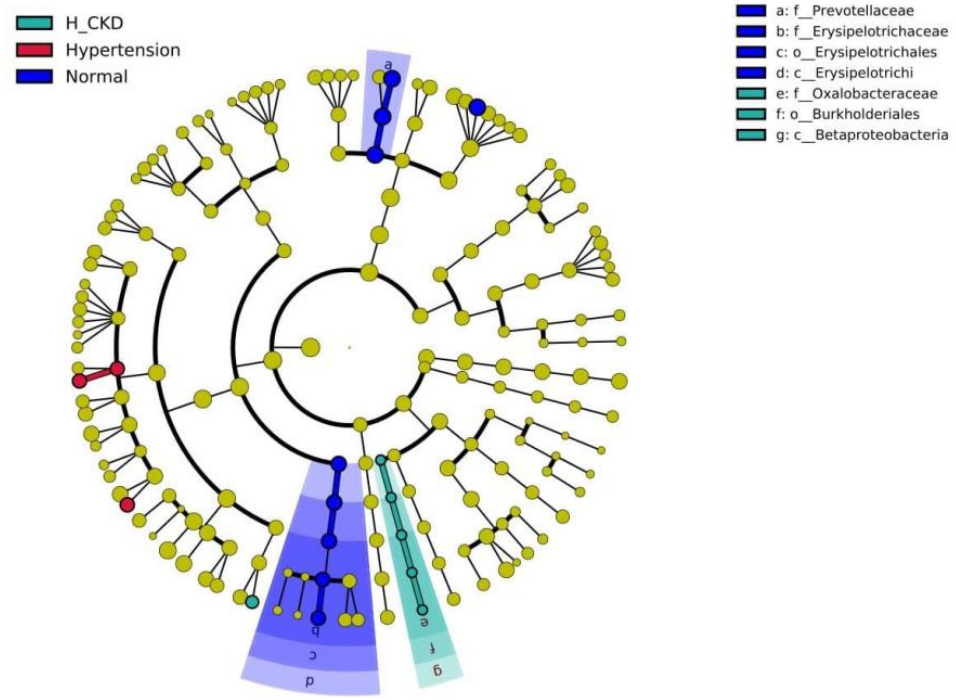
Figure 2: Variations of Fecal Microbiota in H-CKD, Hypertension and Normal Groups

(a) Relative proportions of bacterial phyla in H-CKD $(n=11)$, hypertension $(n=30)$ and normal ( $n=10)$; (b) Rate of relative proportions of Firmicutes and Bacteroidetes (F/B). F/B in both $\mathrm{H}$ CKD and hypertensive groups is significantly lower than it in healthy controls; (c)(d) Linear discriminant analysis (LDA) effect size analysis revealed that the relative abundance of 19 bacteria were significantly different among H-CKD, hypertension and normal groups.

\section{- Figure 3}

Figure 3a

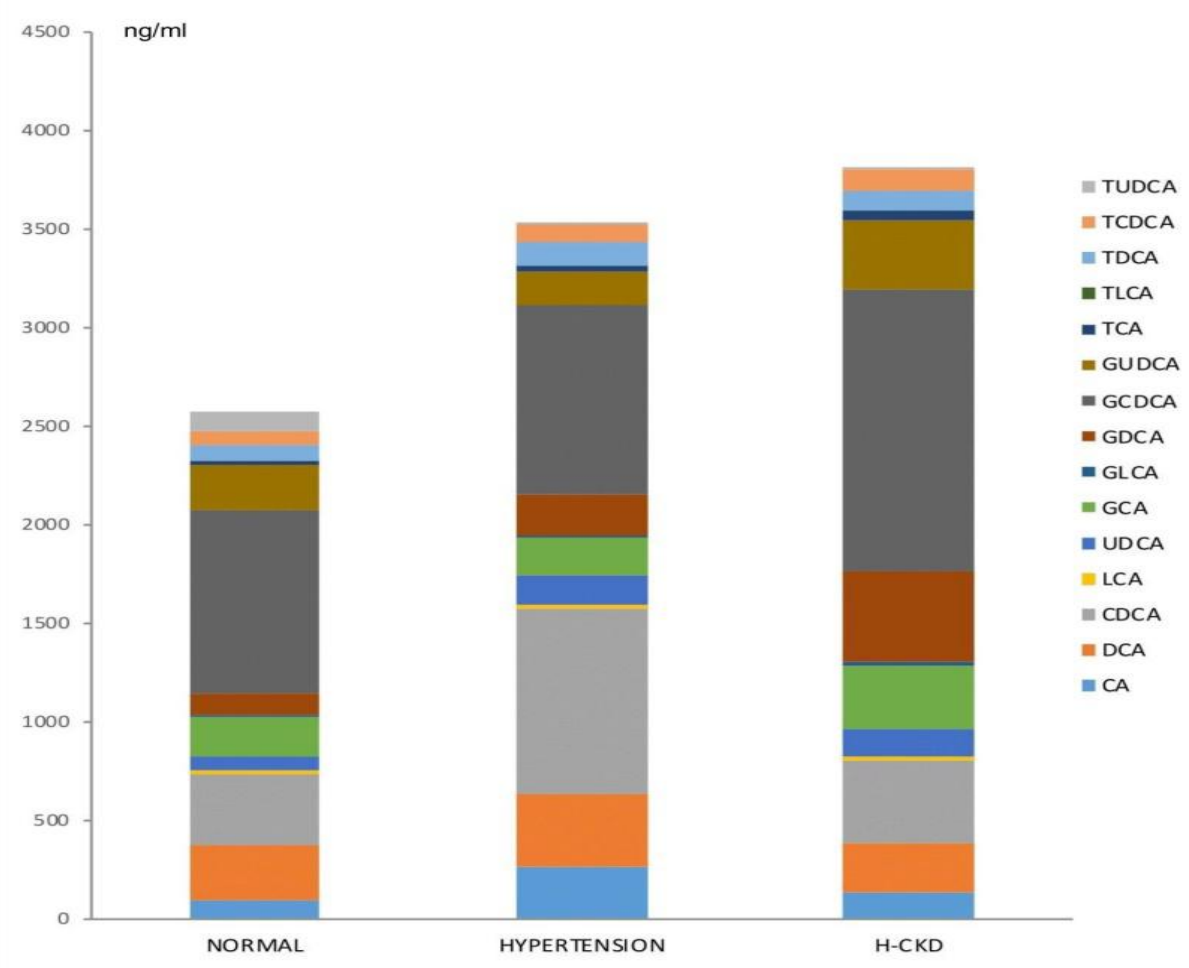


Figure $3 b$

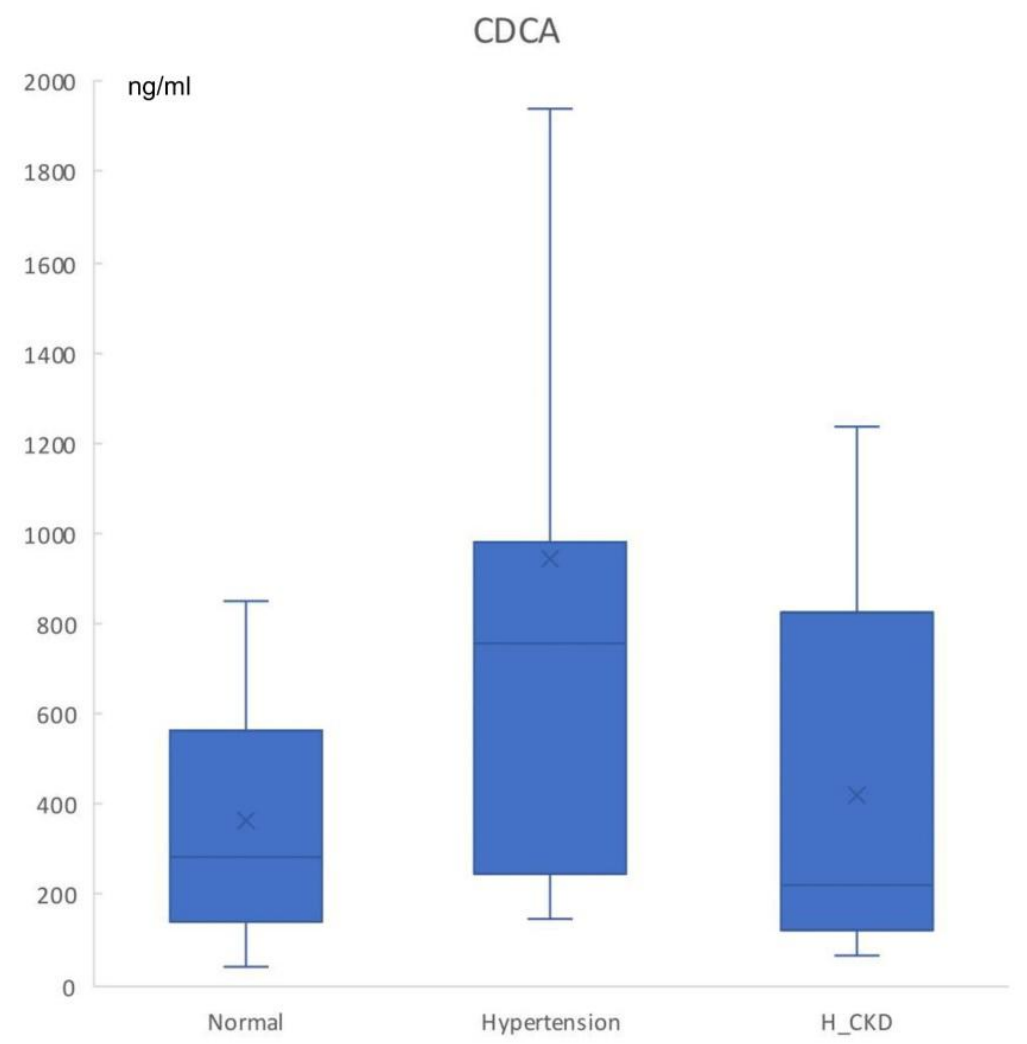

Figure $3 c$

\section{TCA}

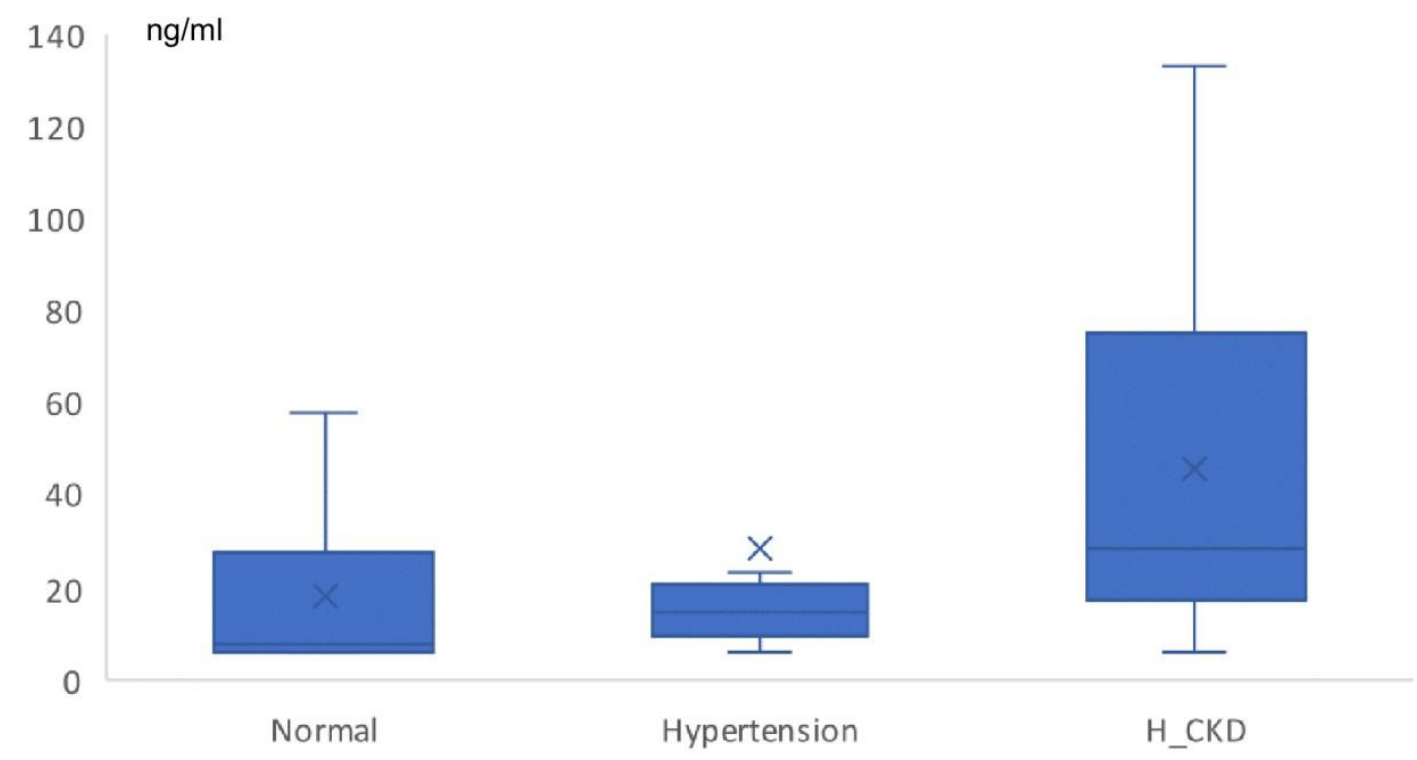


Figure 3d

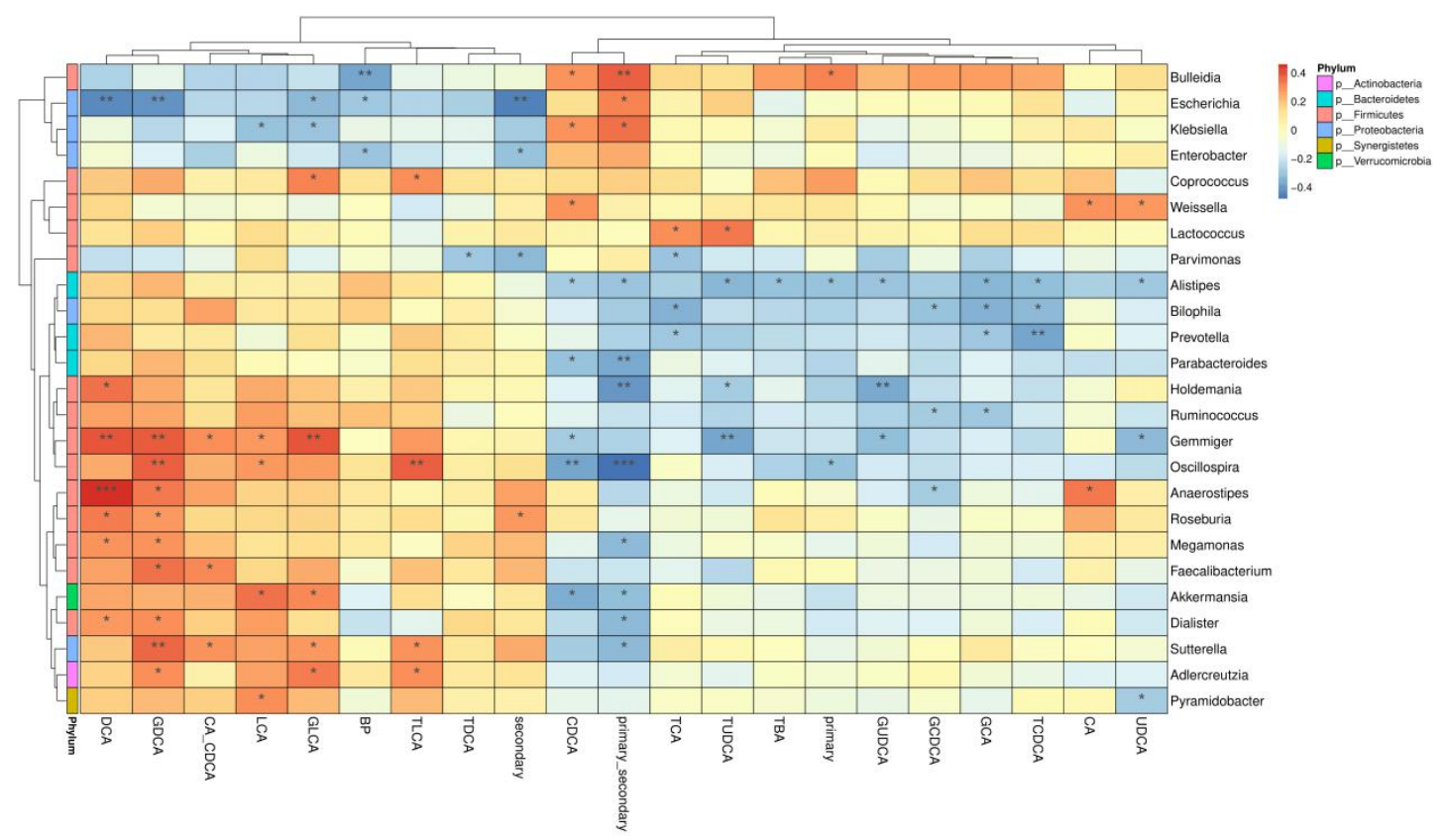

Figure 3: The Relationship between Gut Microbiota and Bile Acid Metabolism in H-CKD and Hypertension Groups.

(a) Different contents of bile acid metabolism among the Normal, H-CKD and Hypertension groups. (b) The concentration of CDCA is significantly different among groups by hypertension and the normal group was observed. (d) The heatmap shows that partial Spearman correlation coefficients between genera and bile acid metabolism. * : $0.01<p \leq 0.05,{ }^{* *}: 0.001<p \leq 0.01,{ }^{* * *}: p \leq 0.001$. 


\section{- Figure 4}

Figure $4 a$

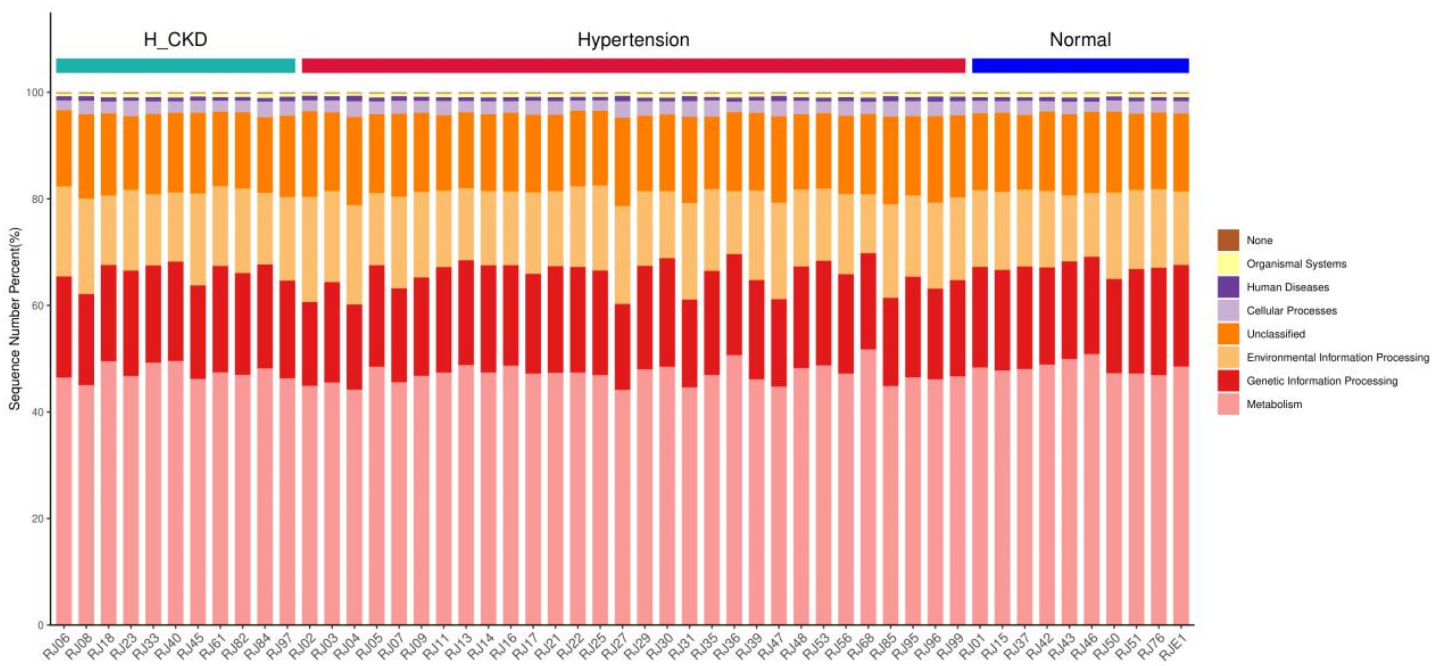

Figure $4 b$

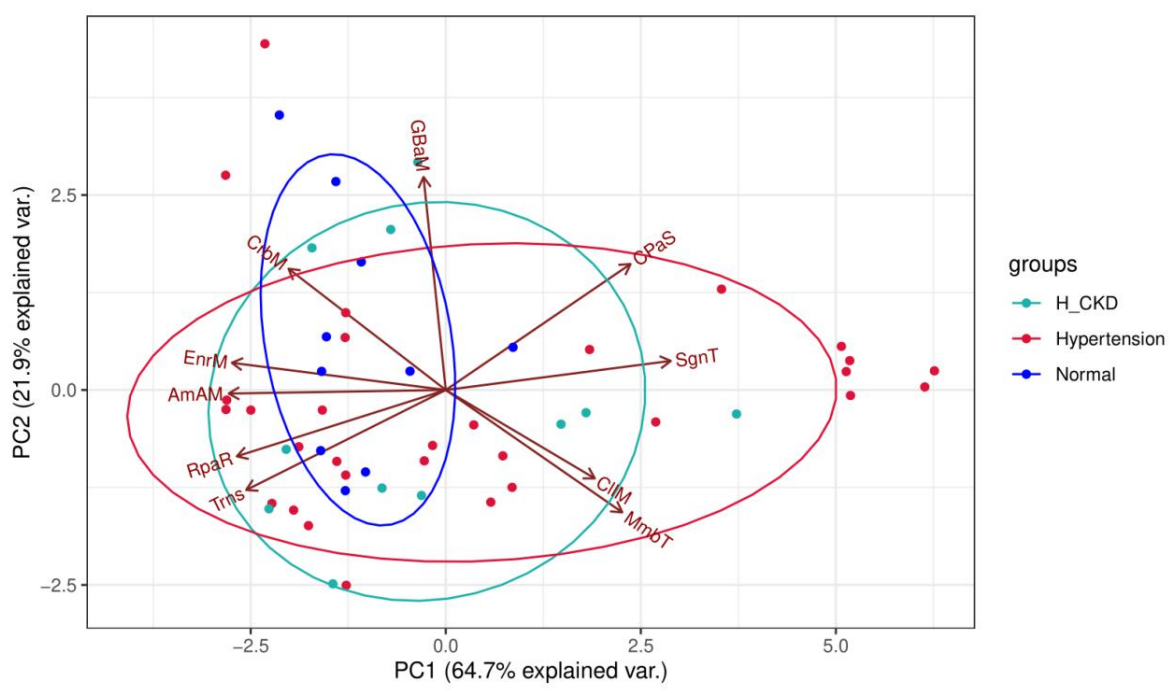

Figure 4: Predicted Metagenomes Functional Analysis

(a) Different relative abundance predicted function of gut bacteria in all individuals. (b) PC1 represents the first principal component, and the percentage represents the contribution of 
the first principal component to the sample difference; PC2 represents the second principal component, and the percentage represents the contribution of the second principal component to the sample difference. The direction and length of the arrow represent the degree of dominance of the prediction function in the sample/group in that direction, the longer the length, the stronger the dominance.

- Table 1. Characteristics information of Experimental Groups

\begin{tabular}{|c|c|c|c|c|c|}
\hline Characteristics & Normal & HBP & H-CKD & $\mathrm{P}$ & $\mathrm{P}$ \\
\hline & $n=10$ & $n=30$ & $\mathrm{n}=11$ & Normal vs HBP & HBP vs H-CKD \\
\hline \multicolumn{6}{|l|}{ Demographics } \\
\hline Age,years median (Q1-Q3) & $45(42.0-51.5)$ & $52.0(40.0-65.3)$ & $55.0(43.5-64.5)$ & 0.109 & 0.116 \\
\hline Gender,female,n(\%) & $5(50.0 \%)$ & $14(46.7 \%)$ & $5(45.5 \%)$ & 0.067 & 0.062 \\
\hline $\mathrm{BMI}, \mathrm{Kg} / \mathrm{m}^{2}$, median,(Q1-Q3) & $22.3(21.0-24.3)$ & $24.1(22.9-25.8)$ & $23.1(22.4-24.8)$ & 0.055 & 0.054 \\
\hline \multicolumn{6}{|l|}{ Behavior } \\
\hline Smoke,yes,n(\%) & $1(10.0 \%)$ & $12(40.0 \%)$ & $5(45.6 \%)$ & 0.05 & 0.055 \\
\hline Alcohol,yes,n(\%) & $2(20.0 \%)$ & $10(33.3 \%)$ & $4(36.4 \%)$ & 0.074 & 0.084 \\
\hline \multicolumn{6}{|l|}{ Hypertension } \\
\hline History,yes,n(\%) & $3(33.3 \%)$ & $23(76.7 \%)$ & $8(63.9 \%)$ & 0.001 & 0.001 \\
\hline Hgrade-1,n(\%) & -- & $4(13.3 \%)$ & $1(9.0 \%)$ & -- & -- \\
\hline Hgrade-2,n(\%) & -- & $6(20.0 \%)$ & $6(54.5 \%)$ & -- & -- \\
\hline Hgrade-3,n(\%) & -- & $6(20.0 \%)$ & $4(39.1 \%)$ & -- & -- \\
\hline Drug,no,n(\%) & -- & $9(30.0 \%)$ & $6(54.5 \%)$ & -- & 0.032 \\
\hline \multicolumn{6}{|l|}{ Time, $\mathbf{n}(\%)$} \\
\hline 0-5years & -- & $22(73.3 \%)$ & $7(63.6 \%)$ & -- & 0.010 \\
\hline 5-10years & -- & $6(20.0 \%)$ & $3(27.2 \%)$ & -- & -- \\
\hline >10years & -- & $2(6.7 \%)$ & $1(9.1 \%)$ & -- & -- \\
\hline
\end{tabular}

BMI: Body Mass Index; History: Family history of early-onset cardiovascular and cerebrovascular disease ; Hgrade: Hypertensive grade; Drug: Five categories of commonly used antihypertensive drugs; Time: Time of hypertension or H-CKD. 
- Table2. Abbreviation and Full Terms of Bile Acids

\begin{tabular}{|l|l|}
\hline Abbreviation Terms & Full Terms \\
\hline CA & Cholic acid \\
\hline DCA & Deoxycholic acid \\
\hline CDCA & Chenodeoxycholic acid \\
\hline LCA & Lithocholic acid \\
\hline UDCA & Ursodeoxycholic acid \\
\hline GCA & Glycocholic acid \\
\hline GLCA & Glycolithocholic acid \\
\hline GDCA & Glycodeoxycholic acid \\
\hline GCDCA & Glycochenodeoxycholic acid \\
\hline GUDCA & Glycoursodeoxycholic acid \\
\hline TCA & Taurocholic acid \\
\hline TLCA & Taurolithocholic acid \\
\hline TDCA & Taurodeoxycholic acid, \\
\hline TCDCA & Taurochenodeoxycholic acid \\
\hline TUDCA & Tauroursodeoxycholic acid \\
\hline
\end{tabular}

Table3. Abbreviation and Full Terms of Metabolic Functions

\begin{tabular}{|l|l|}
\hline Abbreviation Terms & Full Terms \\
\hline CPaS & Cellular Processes and Signaling \\
\hline Trns & Translation \\
\hline EnrM & Energy Metabolism \\
\hline RpaR & Replication and Repair \\
\hline AmAM & Amino Acid Metabolism \\
\hline CrbM & Carbohydrate Metabolism \\
\hline MmpT & Membrane Transport \\
\hline SgnT & Signal Transduction \\
\hline MmbT & Membrane Transport \\
\hline CIIM & Cell Motility \\
\hline GBaM & Glycan Biosynthesis and Metabolism \\
\hline EnrM: & Energy Metabolism \\
\hline
\end{tabular}


Figures
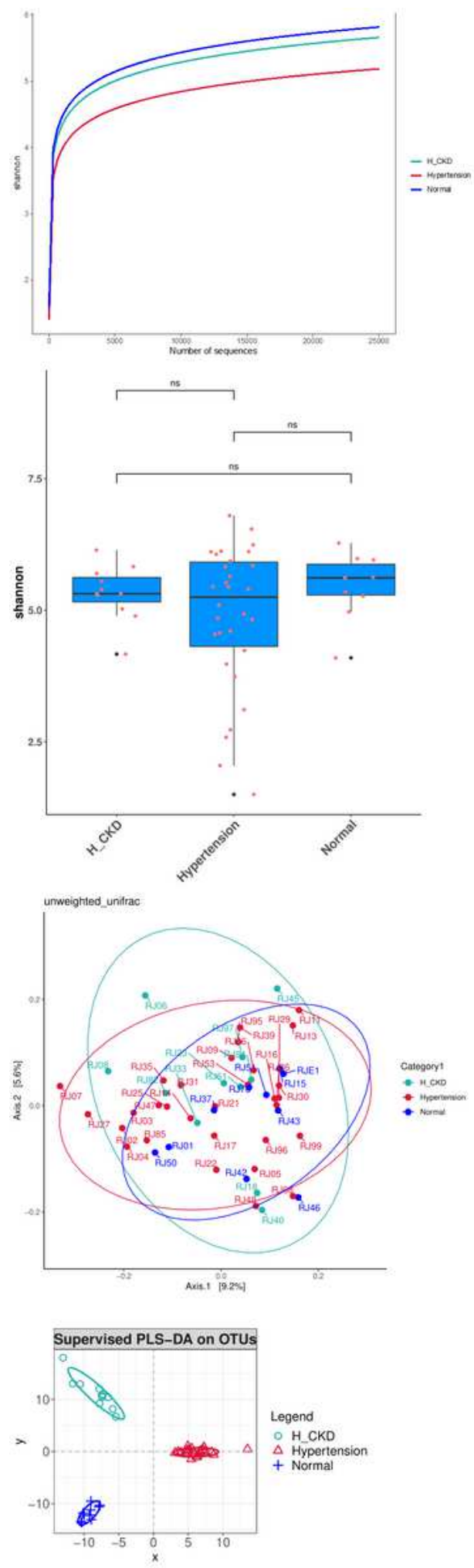

Figure 1

Comparisons of Alpha-diversity and Beta-diversity among the Groups of H-CKD, Hypertension and Normal (a) Rarefaction curves for the mean of Shannon index in the three groups. The curve in each group is near smooth when the sequencing data is abundant enough with few new OTUs undetected; (b) Comparison 
of diversity in the three groups accessed by Shannon index. Compared with the control group tested by Kruskal-Wallis, the a diversity of H-CKD group and hypertensive groups did not significantly decrease at the genus level; (c) Based on the unweighted UniFrac matrix, PCoA showed that the overall fecal microbiota composition of the three groups was similar; (d) PL (b) S-DA shows the significant distinction among the three groups. OTU, operational taxonomic units; PCoA, principal coordinate analysis; PLS-DA, Partial Least Squares Discrimination Analysis.
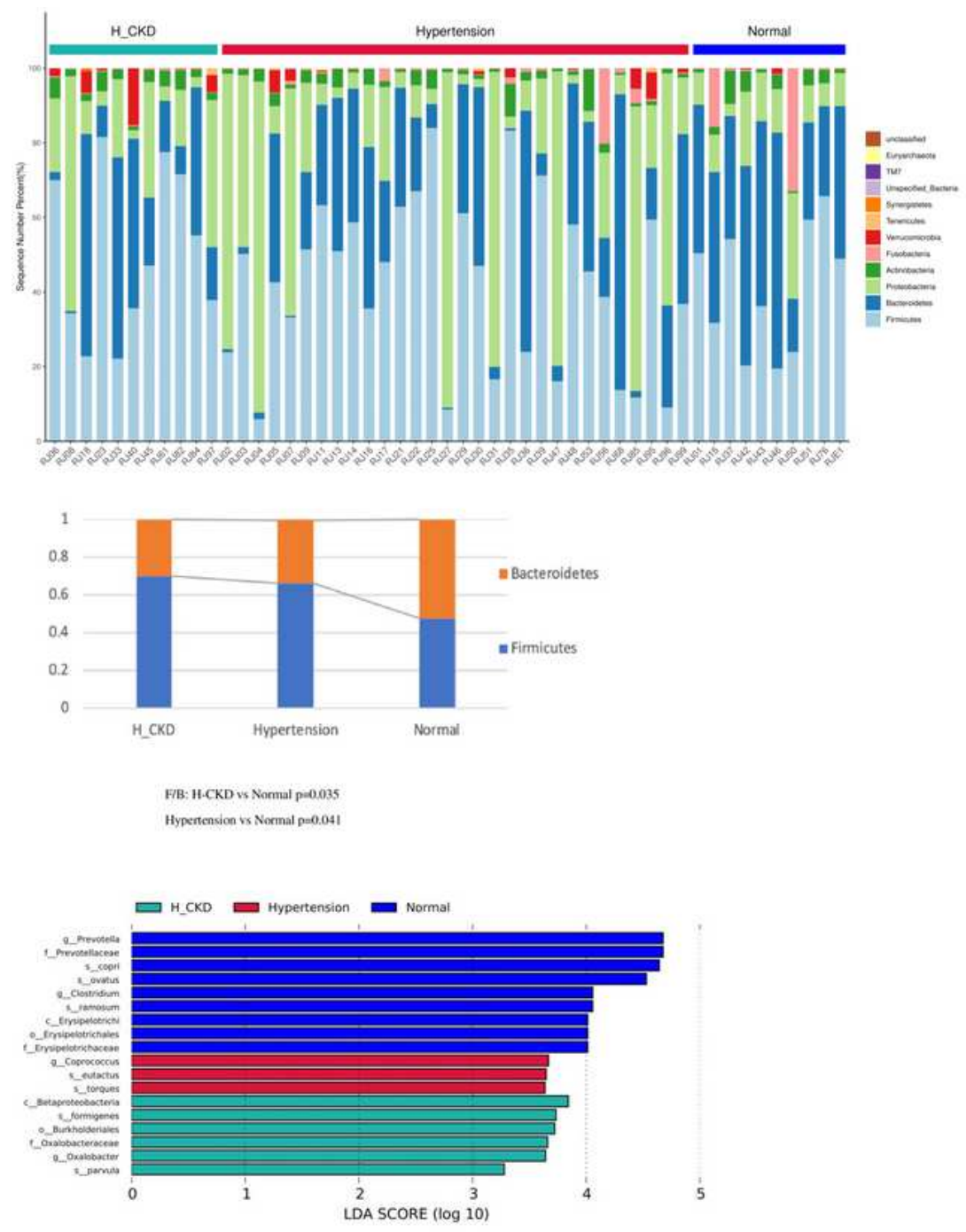

Cladogram

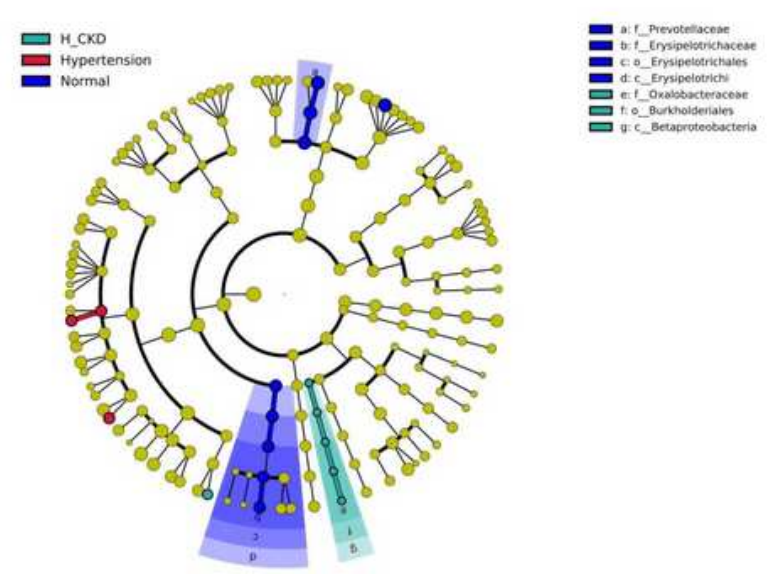

Figure 2 
Variations of Fecal Microbiota in H-CKD, Hypertension and Normal Groups (a) Relative proportions of bacterial phyla in H-CKD $(n=11)$, hypertension $(n=30)$ and normal $(n=10)$; (b) Rate of relative proportions of Firmicutes and Bacteroidetes (F/B). F/B in both HCKD and hypertensive groups is significantly lower than it in healthy controls; (c)(d) Linear discriminant analysis (LDA) effect size analysis revealed that the relative abundance of 19 bacteria were significantly different among $\mathrm{H}-\mathrm{CKD}$, hypertension and normal groups.
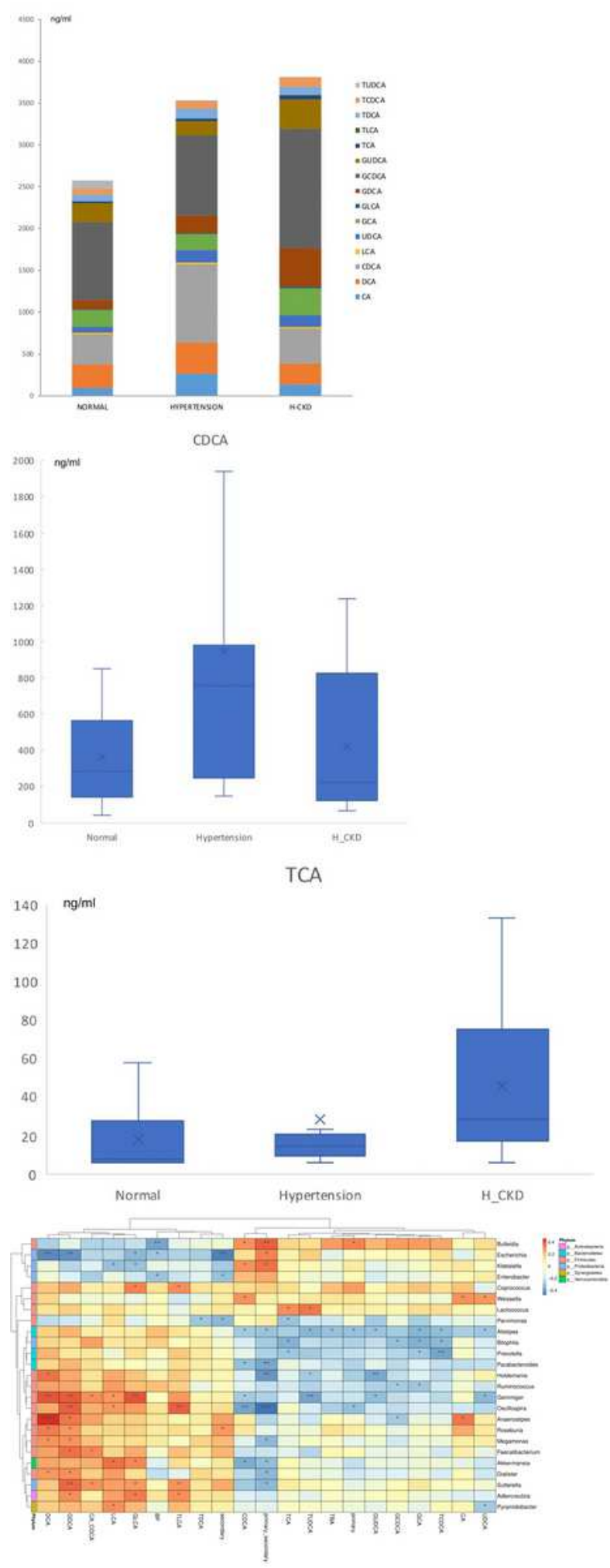

Figure 3 
The Relationship between Gut Microbiota and Bile Acid Metabolism in H-CKD and Hypertension Groups. (a) Different contents of bile acid metabolism among the Normal, H-CKD and Hypertension groups. (b) The concentration of CDCA is significantly different among groups by hypertension and the normal group was observed. (d) The heatmap shows that partial Spearman correlation coefficients between genera and bile acid metabolism. $* \otimes 0.01<p \leq 0.05 \rrbracket * \star \otimes 0.001<p \leq 0.01 \rrbracket * \star \star \otimes p \leq 0.001$.
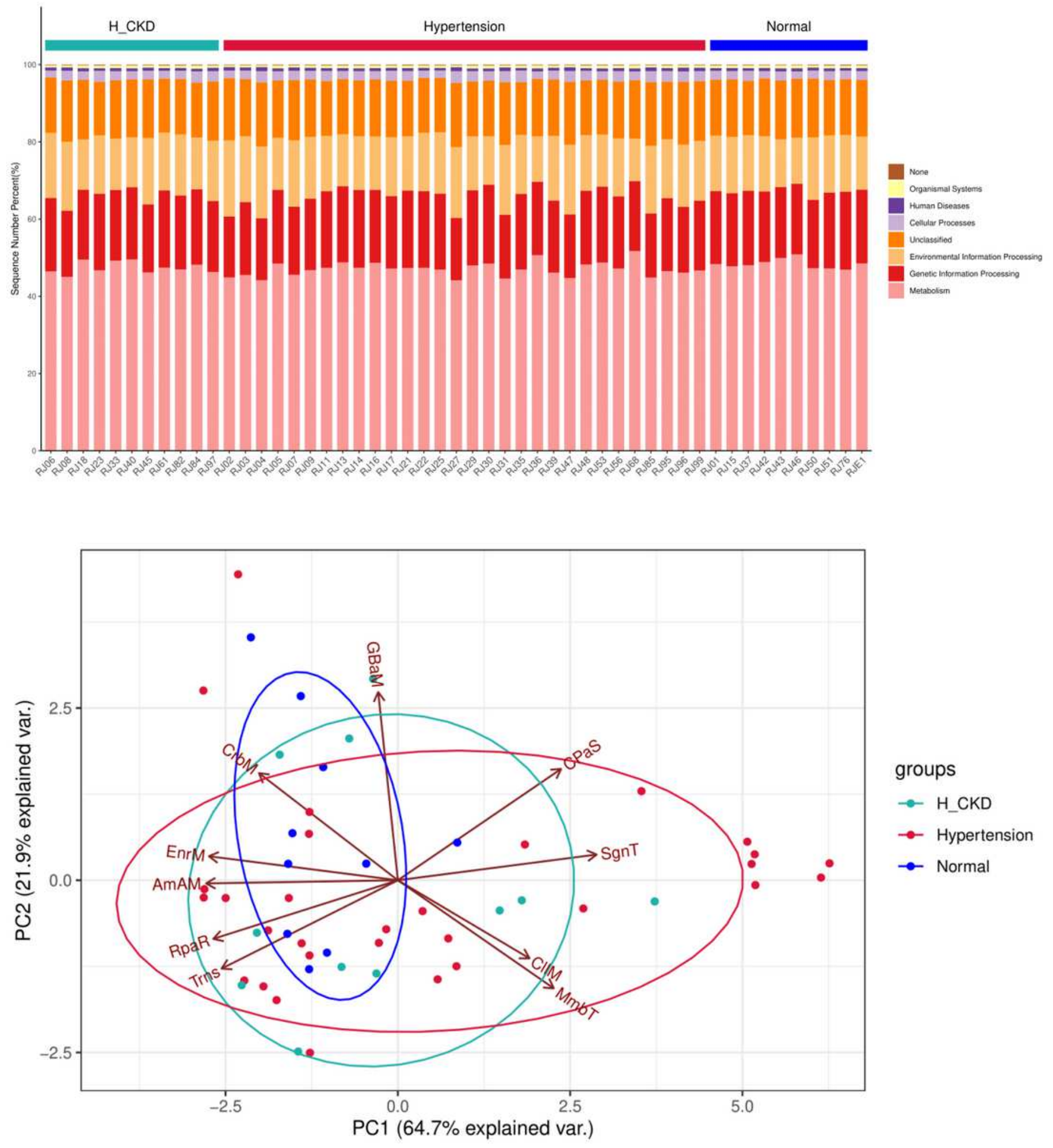

Figure 4 
Predicted Metagenomes Functional Analysis (a) Different relative abundance predicted function of gut bacteria in all individuals. (b) PC1 represents the first principal component, and the percentage represents the contribution of the first principal component to the sample difference; PC2 represents the second principal component, and the percentage represents the contribution of the second principal component to the sample difference. The direction and length of the arrow represent the degree of dominance of the prediction function in the sample/group in that direction, the longer the length, the stronger the dominance. 